\title{
Estimation of Bond Dissociation Energies and Radical Stabilization Energies by ESR Spectroscopy
}

\author{
J ochen J . Brocks, ${ }^{\dagger}$ Hans-Dieter Beckhaus, ${ }^{\dagger}$ Athelstan L. J . Beckwith, ${ }^{*, \neq}$ and \\ Christoph Rüchardt*,† \\ Institut für Organische Chemie and Biochemie der Universität Freiburg, Albertstrasse 21, \\ D-79104 Freiburg i. Br., Germany, and Department of Chemistry, Australian National University,
} Canberra 0200, Australia

Received October 21, 1997

\begin{abstract}
Correlations of various indices of the stability and reactivity of carbon-centered radicals with ESR hyperfine splitting constants have been examined. For a large number of mono- and disubstituted radicals there is a moderately good linear correlation of $\alpha$-proton hyperfine splitting constants $\left(\mathrm{a}\left(\mathrm{H}_{\alpha}\right)\right)$ with radical stabilization enthal pies (RSE) and with $\mathrm{BDE}(\mathrm{C}-\mathrm{H})$, the $\mathrm{C}-\mathrm{H}$ bond dissociation energies for the corresponding parent compounds determined from thermodynamic and kinetic studies of $\mathrm{C}-\mathrm{C}$ homolysis reactions. There is a similarly satisfactory linear correlation of $\mathrm{a}\left(\mathrm{H}_{\alpha}\right)$ with $\mathrm{BDE}-$ $(\mathrm{C}-\mathrm{H})$ determined by Bordwell's electrochemical and acidity function method. In all cases the correlations fail for nonplanar radicals. As expected, $\beta$-proton hyperfine splitting constants $\left(a\left(H_{\beta} \mathrm{Me}\right)\right)$ for radicals with a freely rotating methyl substituent are less sensitive to deviations from planarity and give better linear correlations with RSE and BDE $(\mathrm{C}-\mathrm{H})$. The correlations cover a range of more than $20 \mathrm{kcal} / \mathrm{mol}$ and are reliable predictors of RSE and BDE $(\mathrm{C}-\mathrm{H})$ for a variety of radicals including captodative species. However, the correlations fail for si gnificantly nonplanar radicals and for radicals with cyclic del ocalized systems, e.g., cyclopentadienyl. The ratio a $\left(\mathrm{H}_{\beta} \mathrm{Me}\right) /$ $\mathrm{a}\left(\mathrm{H}_{\alpha}\right)$ for suitably substituted radicals provides an index of pyramidalization and allows one to decide for which compounds values of RSE and $\operatorname{BDE}(\mathrm{C}-\mathrm{H})$ can be confidently estimated.
\end{abstract}

\section{Introduction}

Radical stabilization energies and bond dissociation enthalpies (BDE) are useful for the prediction or interpretation of reactivity and selectivity in free radical chemistry. Values of stabilization energy or of BDE (C$\mathrm{H}$ ) cannot be measured directly but must be deduced indirectly from the results of thermochemical, kinetic, or electrochemical experiments. Thus the quality and comparability of values measured by different techniques depend both on the accuracy of the experimental data and on their interpretation. Consequently, it is sometimes difficult to assess the validity of a new method or even the accuracy of a single value in a series obtained by similar measurements. This is particularly so if no appropriate comparable data are available in the literature.

In a recent paper, ${ }^{1}$ we examined the relationship of radical stabilization enthalpy (RSE) to the $\alpha$-proton ESR hyperfine splitting constant $\left(a\left(\mathrm{H}_{\alpha}\right)\right)$ for 15 different radicals including unsaturated and captodative species. The values of RSE ranged over $22 \mathrm{kcal} / \mathrm{mol}$ and of a $\left(\mathrm{H}_{\alpha}\right)$ over $14 \mathrm{G}$. A good linear correlation was observed. In the present study, we extend this approach to further examples and show that it is possible to use both $\alpha$ - and $\beta$-proton hyperfine splitting constants to predict values of RSE and $\mathrm{BDE}(\mathrm{C}-\mathrm{H})$ and to estimate the consistency of a series of data.

\footnotetext{
† Universität Freiburg.
}

‡ Australian National University.

(1) Welle, F. M.; Beckhaus, H.-D.; Rüchardt, C. J . Org. Chem. 1997, $62,552-558$.

(2) Fischer, H. Z. Naturforsch. 1964, 19a, 855-867. Fischer, H. Z. Naturforsch. 1965, 20a, 428-432.

(3) For a discussion of factors affecting deviations from planarity of radicals including the cyclopropyl and oxiranyl radicals, see ref 4 .
Early work ${ }^{2}$ on the factors affecting the magnitudes of $\mathrm{a}\left(\mathrm{H}_{\alpha}\right)$ and $\mathrm{a}\left(\mathrm{H}_{\beta}\right)$ showed that for planar carbon-centered radicals

$$
\begin{gathered}
\mathrm{a}\left(\mathrm{H}_{\alpha}\right)=\mathrm{Q}_{\alpha} \rho\left(\mathrm{C}_{\alpha}\right) \\
\mathrm{a}\left(\mathrm{H}_{\beta} \mathrm{Me}\right)=\mathrm{Q}_{\beta} \rho\left(\mathrm{C}_{\alpha}\right)
\end{gathered}
$$

where $\rho\left(\mathbf{C}_{\alpha}\right)$ is the spin density on the radical center, $\mathbf{Q}_{\alpha}$ and $\mathrm{Q}_{\beta}$ are constants, and $\mathrm{a}\left(\mathrm{H}_{\beta} \mathrm{Me}\right)$ is the $\beta$-proton hyperfine splitting constant for a freely rotating methyl group attached directly to the radical center. On the basis of eqs 1 and 2, it should be possible to use either $\mathrm{a}\left(\mathrm{H}_{\alpha}\right)$ or $\mathrm{a}\left(\mathrm{H}_{\beta} \mathrm{Me}\right)$ to determine values of $\alpha$-spin density, and hence the degree of del ocalization of the free electron. However, the development of quantitative relationships between hyperfine coupling constants and radical stabilization or BDE is complicated by the fact that eqs 1 and 2 are not valid for nonplanar radicals. Deviations from planarity due to strain, such as occurs for cyclopropyl and other small cyclic radicals, ${ }^{3}$ or from the effect of electronegative $\alpha$-substituents, e.g., halogen, ${ }^{3}$ oxygen, ${ }^{4}$ or nitrogen, ${ }^{5}$ lower the values of $\mathrm{Q}_{\alpha}$ and $\mathrm{Q}_{\beta}$. Nevertheless, there have been a number of earlier attempts to correlate stabilization energies or bond dissociation energies with $\mathrm{a}\left(\mathrm{H}_{\alpha}\right)$ or $\mathrm{a}\left(\mathrm{H}_{\beta} \mathrm{Me}\right)$. Most such studies have involved $\mathrm{a}\left(\mathrm{H}_{\alpha}\right)$.

In one of the earlier papers, Green and Walton ${ }^{6}$ reported that stabilization energies (SE ${ }^{\mathrm{ESR}}$ ) derived ex-

(4) Dobbs, A. J .; Gilbert, B. C.; Norman, R. O. C. J . Chem. Soc. A 1971, 124-135.

(5) Armstrong, D. A.; Rank, A.; Yu, D. J . Am. Chem. Soc. 1993, 115, 666-673; J . Am. Chem. Soc. 1994, 116, 8432. Shaffer, S. A.; Turecek, F.; Ceruy, R. L. J . Am. Chem. Soc. 1993, 115, 12117-12124.

(6) Green, I. G.; Walton, J . C. J . Chem. Soc., Perkin Trans. 21984 $1253-1257$. 
clusively from experimental ESR rotational barriers gave a linear relationship when plotted against $\log \left(a\left(\mathrm{H}_{\alpha}\right)\right)$, where $\mathrm{a}\left(\mathrm{H}_{\alpha}\right)$ is the proton hyperfine splitting for the terminal methylene groups of polyenyl radicals. In contrast, Nicholas and Arnold ${ }^{7}$ found a linear relationship between $\mathrm{a}\left(\mathrm{H}_{\alpha}\right)$ and SE ${ }^{\mathrm{ESR}}$ for similar species. Nonhebel and Walton ${ }^{8}$ examined the relationship between the rotational barriers and $\mathrm{a}\left(\mathrm{H}_{\alpha}\right)$ for some saturated radicals and found a linear correlation, while Leroy et al. ${ }^{9}$ showed that there also exists a linear relationship between the $\rho\left(C_{\alpha}\right)$ of six captodative radicals and their relative stabilization energies determined by ab initio calculations. Other examples of attempts to correlate hyperfine splitting constants with factors related to stabilization energies include Stein's linear correlations of the kinetically determined $\mathrm{BDE}(\mathrm{C}-\mathrm{C})$ of substituted ethylbenzenes with the benzylic hyperfine splitting constant ${ }^{10}$ and of the BDE $(\mathrm{C}-\mathrm{O})$ of substituted anisoles with the hyperfine splitting constants for the ortho and para protons in substituted phenoxy radicals. ${ }^{11}$

For aromatic compounds, Arnold et al..$^{12}$ have published extensive lists of substituent constants $\sigma_{\alpha}{ }^{\circ}(\mathrm{X})$ for metaand para-substituted benzyl radicals. $\sigma_{\alpha}{ }^{\circ}(X)$ is defined by $\sigma_{\alpha}{ }^{\circ}(\mathrm{X})=1-\mathrm{a}\left(\mathrm{H}_{\alpha}(\mathrm{X})\right) / \mathrm{a}\left(\mathrm{H}_{\alpha}(0)\right)$, where $\mathrm{a}\left(\mathrm{H}_{\alpha}(\mathrm{X})\right)$ is the hyperfine splitting of the benzylic proton in the substituted benzyl radical and $\mathrm{a}\left(\mathrm{H}_{\alpha}(0)\right)$ is the corresponding splitting for the benzyl radical. The $\sigma_{\alpha}{ }^{*}$ scale gives good linear correlations with the rates of various radical reactions in Taft equations. Similar results involving extensive tables of $\sigma^{*}$ have been reported by J ackson et al. ${ }^{13}$ Very recently a $\sigma^{*}$ scale based on the ESR D parameter for substituted 1,3-arylcyclopentane-1,3-diyl radicals has been published. ${ }^{14}$

As $Q_{\beta}$ (eq 2) is less diminished by pyramidalization of the radical center than is $Q_{\alpha}$ (eq 1 ), one might expect that values of $\mathrm{a}\left(\mathrm{H}_{\beta} \mathrm{Me}\right)$ would give a better correlation with indices of radical stabilization than do values of $a\left(\mathrm{H}_{\alpha}\right)^{2,4}$ Although Norman et al. ${ }^{4}$ had earlier noted that there is a good correlation of $\mathrm{a}\left(\mathrm{H}_{\beta} \mathrm{Me}\right)$ with $\rho\left(\mathrm{C}_{\alpha}\right)$, the only correlation of $\mathrm{a}\left(\mathrm{H}_{\beta} \mathrm{Me}\right)$ with radical reactivity appears to be that of Afanas'ev who devel oped a Taft equation for the rates of radical substitution reactions. ${ }^{15} \mathrm{He}$ found that there is a good linear correlation between $\sigma^{*}$ and $\mathrm{a}\left(\mathrm{H}_{\beta} \mathrm{Me}\right)$ for radicals of the type $\mathrm{X}\left(\mathrm{CH}_{3}\right) \mathrm{HC}$.

Despite the undoubted utility of some of the correlations outlined above, there remains the question of which type of hyperfine splitting gives the best correlations with consistent and reliable indicators of radical stability and

(7) Nicholas, A. M. de P.; Arnold, D. R. Can. J . Chem. 1986, 64 $270-276$

(8) Nonhebel, D. C.; Walton, J . C. J . Chem. Soc., Chem. Commun. 1984, 731-732.

(9) Leroy, G.; Peeters, D.; Sana, M.; Wilante, C. Bull. Soc. Chim. Belg. 1988, 97, 1003-1010.

(10) Suryan, M. M.; Stein, S. E. J . Phys. Chem. 1989, 93, 73627365.

(11) Suryan, M. M.; Kafafi, S. A.; Stein, S. E. J . Am. Chem. Soc. 1996, 118, 775-778.

(12) Dust, J . M.; Arnold, D. R. J . Am. Chem. Soc. 1983, 105, 12211227. Wayner, D. D. M.; Arnold, D. R. Can. J . Chem. 1984, 62, 11641168. Wayner, D. D. M.; Arnold, D. R. J . Am. Chem. Soc. 1983, 105 6531.

(13) J ackson, R. A.; Sharifi, M. J . Chem. Soc., Perkin Trans. 21984 1253-1257 and references therein.

(14) Adam, W.; Harrer, H. M.; Kita, F.; Korth, H.-G.; Nau W. M. J Org. Chem. 1997, 62, 1419-1426.

(15) Afanas'ev, B. Int. J . Chem. Kinetics 1975, 7, 857-877.

(16) Rüchardt, C.; Beckhaus, H.-D. Top. Curr. Chem. 1985, 130, 1-22. For more recent references to this method for determining RSE and $\operatorname{BDE}(\mathrm{C}-\mathrm{H})$, see ref 1. reactivity. In the present work we have compared correlations of $\mathrm{a}\left(\mathrm{H}_{\alpha}\right)$ and of $\mathrm{a}\left(\mathrm{H}_{\beta} \mathrm{Me}\right)$ with $\mathrm{BDE}(\mathrm{C}-\mathrm{H})$ and with Rüchardt's radical stabilization enthalpies (RSE). ${ }^{16}$

\section{Results and Discussion}

Indices of Radical Stability and Reactivity. Although it is clear that a decrease in $\alpha$-spin density represents delocalization of the free electron, it is not axiomatic that different mechanisms of spin distribution, such as $\pi$-delocalization, hyperconjugation, spin polarization, and anomeric interactions, will each lead to the same increase in radical stabilization for the same degree of spin delocalization. ${ }^{17}$ Furthermore, there are other factors that may influence the stabilization energy as estimated from $\triangle B D E(C-H)$ or $\triangle B D E(C-C)$. They include interactions between substituents such as van der Waals repulsions, dipolar effects, hydrogen bonding, and hydrophobic interactions, all of which contribute to the difference in strain enthalpy between a radical and its precursor. To minimize the importance of such effects, we have used radical stabilization enthal py (RSE) defined as the difference in stability between a purely hydrocarbon radical ${ }^{\circ} \mathrm{CXYZ}(\mathrm{X}, \mathrm{Y}, \mathrm{Z}=\mathrm{H}$ or alkyl) and the corresponding substituted radicals ${ }^{\circ} \mathrm{CXYZ}(\mathrm{X}=\mathrm{H}$ or al kyl; $Y=H$, alkyl or functional group; $Z=$ functional group), i.e., the difference in stability between a purely hydrocarbon radical and its analogue in which one or more of the al kyl groups have been replaced by substituents. One of the advantages of the use of RSE's is that they avoid the problem that values of differences in $\operatorname{BDE}(\mathrm{C}-\mathrm{H})$ clearly do not correspond accurately to the differences in stability between primary, secondary, and tertiary alkyl radicals. Extensive compilations of values of RSE based on thermochemical and kinetic data for the homolysis of $\mathrm{C}-\mathrm{C}$ bonds are available. ${ }^{16}$

Despite the fact that they include contributions arising from the release of strain in the precursor molecule and differences between other nonbonded interactions in the precursor and the radical, values of $\mathrm{BDE}(\mathrm{C}-\mathrm{H})$ for the parent compound are widely used to estimate the relative stabilities and reactivities of radicals. McMillen and Golden's early review ${ }^{18}$ includes extensive lists of BDE$(\mathrm{C}-\mathrm{H})$ values taken from the literature, while more recently Tsang ${ }^{19}$ has published a selection of "best" values. An excellent self-consistent series of $\operatorname{BDE}(\mathrm{C}-$ $\mathrm{H})$ has been experimentally determined by Bordwell using a combination of electrochemical and acidity function measurements. ${ }^{20}$ Values of $\mathrm{BDE}(\mathrm{C}-\mathrm{H})$ are also

(17) For a comment, see: Sustmann, R.; Korth, H. G. Adv. Phys Org. Chem. 1990, 26, 131-178.

(18) McMillen, D. F.; Golden, D. M. Annu. Rev. Phys. Chem. 1982 $32,493-532$

(19) Tsang, W. In Energetics of Organic Free Radicals; Somoes, A. M., Greenberg, A., Liebman, F., Eds.; Black Academic and Professional: London, 1996; pp 22-58

(20) (a) Bordwell, F. G.; Zhang, X.-M. Acc. Chem. Res. 1993, 26, 510 517. (b) Bordwell, F. G.; Zhang, X.-M.; Alnajjar, M. S. J . Am. Chem Soc. 1992, 114, 7623-7629. (c) Bordwell, F. G.; Harrelson, J . A.; Zhang X. J . Org. Chem. 1991, 56, 4448-4450. (d) Bordwell, F. G.; Zhang, X.-M.; Filler, R. J . Org. Chem. 1993, 58, 6067-6071. (e) Bordwell, F. G.; Satish, A. V. J . Am. Chem. Soc. 1994, 116, 8885-8889. (f) Bordwell, F. G.; Gallagher, T.; Zhang, X. I. Am. Chem. Soc. 1991, 113, 34953497. (g) Bordwell, F. G.; Cheng, J. P.; Harrelson, J . A. J . Am. Chem. Soc. 1988, 110, 1229-1231. (i) Bordwell, F. G.; Harrelson, J . A.; Satish, A. V. J . Org. Chem. 1989, 54, 3101-3105. (j) Bordwell, F. G.; Cheng J.-P.; J i, G.-Z.; Satish, A. V.; Zhang, X. J . Am. Chem. Soc. 1991, 113, 9790-9795.

(21) (a) Pasto, D. J .; Krasnansky, R.; Zercher, C. J . Org. Chem. 1987, 52, 3062-3072. (b) Pasto, D. J . J . Org. Chem. 1988, 53, 8164-8175. 
Table 1. RSE, BDE(C-H), ESR Parameters, and Pyramidalization Quotients for the Radicals • CXYZ

\begin{tabular}{|c|c|c|c|c|c|c|c|c|c|}
\hline no. & $x$ & $Y$ & Z & $\begin{array}{c}\text { RSEa/ } \\
\text { kcal mol-1 }\end{array}$ & $\begin{array}{c}\mathrm{BDE}(\mathrm{C}-\mathrm{H})^{\mathrm{b}} / \\
\mathrm{kcal} \mathrm{mol}^{-1}\end{array}$ & $a_{\alpha} / G$ & $\mathrm{a}\left(\mathrm{H}_{\beta} \mathrm{Me}\right) / \mathrm{G}$ & $\mathrm{P}^{\mathrm{t} c}$ & $P \sec d$ \\
\hline 1a & $\mathrm{Me}$ & $\mathrm{Me}$ & Me & $\equiv 0$ & $95.7^{e}$ & & $22.71^{f}$ & & \\
\hline $\mathbf{1 b}$ & $\mathrm{Me}$ & $\mathrm{Me}$ & $\mathrm{H}$ & $\equiv 0$ & $98.7^{e}$ & $22.1^{f}$ & $24.7^{f}$ & 1.03 & 1.12 \\
\hline $2 a$ & $\mathrm{Ph}$ & $\mathrm{Me}$ & Me & -8.49 & 87.3 & & $16.5^{f}$ & & \\
\hline $2 b$ & $\mathrm{Ph}$ & $\mathrm{Me}$ & $\mathrm{H}$ & $-8.4^{\mathrm{g}}$ & 90.3 & $16.25^{h}$ & $17.69^{\mathrm{h}}$ & 1.02 & 1.09 \\
\hline $3 a$ & OPri & $\mathrm{Me}$ & Me & $-5.9 i$ & 93.9 & & 19.37j & & \\
\hline $3 \mathbf{b}$ & $O B u^{t}$ & $\mathrm{Me}$ & $\mathrm{H}$ & $-5.9^{i}$ & 96.9 & $13.5^{\mathrm{k}}$ & $21.6^{\mathrm{k}}$ & 1.45 & 1.6 \\
\hline $4 a$ & $\mathrm{NH}_{2}$ & $\mathrm{Me}$ & $\mathrm{Me}$ & -3.9 & 94.2 & & 17.9 & & \\
\hline $\mathbf{4 b}$ & $\mathrm{NH}_{2}$ & $\mathrm{Me}$ & $\mathrm{H}$ & -3.9 & 97.1 & $14.7^{\mathrm{k}}$ & $20.7^{k}$ & 1.22 & 1.41 \\
\hline $5 a$ & COPh & $\mathrm{Me}$ & $\mathrm{Me}$ & $-6.0^{\mathrm{m}}$ & 89.9 & & $19.13^{k}$ & & \\
\hline $5 b$ & COPh & $\mathrm{Me}$ & $\mathrm{H}$ & $-6.0^{m}$ & 92.9 & $18.7^{\mathrm{k}}$ & $21.86^{k}$ & 1.04 & 1.17 \\
\hline $6 a$ & $\mathrm{CO}_{2} \mathrm{Et}$ & $\mathrm{Me}$ & $\mathrm{Me}$ & $-2.8^{m}$ & 92.6 & & $21.56^{f}$ & & \\
\hline $6 b$ & $\mathrm{CO}_{2} \mathrm{Et}$ & $\mathrm{Me}$ & $\mathrm{H}$ & $-2.8^{m}$ & 95.6 & $20.48^{j}$ & 24.68 & 1.05 & 1.21 \\
\hline $7 a$ & $\mathrm{CN}$ & $\mathrm{Me}$ & $\mathrm{Me}$ & $-3.4^{\mathrm{n}}$ & 91.9 & & $20.6^{k}$ & & \\
\hline $7 b$ & $\mathrm{CN}$ & $\mathrm{Me}$ & $\mathrm{H}$ & $-3.4^{n}$ & 94.9 & $20.3^{f}$ & $23.1^{f}$ & 1.01 & 1.13 \\
\hline $8 \mathbf{a}$ & $\mathrm{CO}_{2} \mathrm{Et}$ & $\mathrm{Ph}$ & $\mathrm{Me}$ & $-10.1^{o, p}$ & 85.6 & & $16.60^{q}$ & & \\
\hline $8 b$ & $\mathrm{CO}_{2} \mathrm{Et}$ & $\mathrm{Ph}$ & $\mathrm{H}$ & $-10.1^{o, p}$ & 88.6 & $14.8^{q}$ & & 1.12 & \\
\hline $9 a$ & COMe & COMe & $\mathrm{Me}$ & $-11.4^{r}$ & 84.7 & & $21.52^{j}$ & & \\
\hline $9 b$ & COMe & COMe & $\mathrm{H}$ & $-11.4^{r}$ & 87.7 & $18.0^{j}$ & & 1.16 & \\
\hline $10 \mathbf{a}$ & $\mathrm{CN}$ & $\mathrm{CN}$ & $\mathrm{Me}$ & $-2.5^{n}$ & 84.6 & & $20.64^{j}$ & & \\
\hline $10 b$ & $\mathrm{CN}$ & $\mathrm{CN}$ & $\mathrm{H}$ & $-2.5^{n}$ & 87.6 & $19.22^{\mathrm{j}}$ & & & \\
\hline $11 a$ & $\mathrm{CN}$ & $\mathrm{OH}$ & $\mathrm{Me}$ & $-8.1^{i}$ & 87.3 & & $17.88^{f}$ & 0.97 & \\
\hline $11 b$ & $\mathrm{CN}$ & OMe & $\mathrm{H}$ & $-8.1^{i}$ & 90.3 & $18.4^{k}$ & & & \\
\hline $12 a$ & \multirow{2}{*}{\multicolumn{2}{|c|}{$\begin{array}{l}\text {-CONBuCHMeCONBu- } \\
\text {-CONBuCH}{ }_{2} \mathrm{CONBu}-\end{array}$}} & $\mathrm{Me}$ & $-6.3^{s, p}$ & 89.4 & & $17.8^{j}$ & 1.04 & \\
\hline $12 b$ & & & $\mathrm{H}$ & $-6.3^{s, p}$ & 92.4 & $17.1^{j}$ & & & \\
\hline 13 & $\mathrm{CN}$ & $\mathrm{NH}_{2}$ & $\mathrm{H}$ & $-13.8^{t}$ & 84.9 & $14.9^{k}$ & & & \\
\hline $14 a$ & $\mathrm{CO}_{2} \mathrm{Bu}^{\mathrm{t}}$ & $\mathrm{NH}_{2}$ & $\mathrm{Me}$ & $-14.8^{\mathrm{u}}$ & 81.3 & & $13.2^{v}$ & 1.02 & \\
\hline $14 b$ & $\mathrm{CO}_{2} \mathrm{Me}$ & $\mathrm{NH}_{2}$ & $\mathrm{H}$ & $-14.8^{\mathrm{u}}$ & 84.3 & $13.0^{v}$ & & & \\
\hline 15 & $\mathrm{COPh}$ & $\mathrm{NMe}_{2}$ & $\mathrm{H}$ & $-21.6^{w}$ & 78.3 & $8.5^{x}$ & & & \\
\hline $16 \mathbf{a}$ & $\mathrm{Ph}$ & $\mathrm{Ph}$ & Me & $-12.9^{y}$ & 82.8 & & $15.1^{f}$ & 1.03 & \\
\hline $16 b$ & $\mathrm{Ph}$ & $\mathrm{Ph}$ & $\mathrm{H}$ & $-12.9^{y}$ & 85.8 & $14.7^{f}$ & & & \\
\hline 17 & \multirow{2}{*}{\multicolumn{3}{|c|}{$\begin{array}{l}\text { 9,10-dihydroanthryl-9-yl } \\
\text { 9-methylfluoren-9-yl }\end{array}$}} & $-15.2^{y}$ & 83.5 & $13.4^{\mathrm{g}}$ & & & \\
\hline $18 a$ & \multirow{2}{*}{\multicolumn{3}{|c|}{$\begin{array}{l}\text { 9-methylfluoren-9-yl } \\
\text { fluoren-9-yl }\end{array}$}} & $-16.0^{z}$ & 79.7 & & $14.56^{j}$ & 1.05 & \\
\hline $18 b$ & & & & $-16.0^{z}$ & 82.7 & $13.9^{f}$ & & & \\
\hline $19 a$ & \multicolumn{3}{|c|}{ 9-methylxanth-9-yl } & $-18.1^{y}$ & 77.6 & & $12.2^{\mathrm{f}}$ & 0.96 & \\
\hline $19 b$ & \multicolumn{3}{|c|}{ xanth-9-yl } & $-18.1^{y}$ & 80.6 & $12.7^{f}$ & & & \\
\hline $20 \mathbf{a}$ & $\mathrm{CH}=\mathrm{CH}_{2}$ & $\mathrm{Me}$ & $\mathrm{Me}$ & $-12.6^{y}$ & 83.1 & & $13.8^{f}$ & 0.99 & \\
\hline $20 b$ & $\mathrm{CH}=\mathrm{CH}_{2}$ & $\mathrm{Me}$ & $\mathrm{H}$ & $-12.6^{y}$ & 86.1 & $14.0^{f}$ & $15.2^{\mathrm{f}}$ & & 1.09 \\
\hline 21 & \multicolumn{3}{|c|}{ pentamethylcyclopentadienyl } & $-13.7^{y}$ & $82.0^{\text {aa }}$ & & $6.4^{f}$ & & \\
\hline 22 & \multicolumn{3}{|c|}{ inden-1-yl } & $-15.7^{y}$ & 83.0 & $11.9^{f}$ & & & \\
\hline 23 & \multicolumn{3}{|c|}{ anthron-10-yl } & $-17.8^{\mathrm{bb}}$ & 80.9 & $12.12^{\mathrm{bb}}$ & & & \\
\hline
\end{tabular}

a Reference 16. In most cases RSE is the mean value of RSE for several radicals ${ }^{\circ} \mathrm{CXY} Z$ with different alkyl substituents. ${ }^{b}$ Reference 1. ${ }^{c} \mathrm{P}^{\mathrm{t}}=\mathrm{a}\left(\mathrm{H}_{\beta}{ }^{\mathrm{Me}}(\mathrm{XYMeC} \cdot)\right) / \mathrm{a}\left(\mathrm{H}_{\alpha}(\mathrm{XYHC} \cdot)\right)$. ${ }^{\mathrm{d}} \mathrm{Psec}=\mathrm{a}\left(\mathrm{H}_{\beta} \mathrm{Me}(\mathrm{XHMeC} \cdot)\right) / \mathrm{a}\left(\mathrm{H}_{\alpha}(\mathrm{XHMeC} \cdot)\right)$. ${ }^{\mathrm{e}}$ Reference 19. ${ }^{\mathrm{f}}$ Reference $23 a$. ${ }^{g} \mathrm{Kratt}, \mathrm{G}$.; Beckhaus, H.-D.; Rüchardt, C. Chem. Ber. 1984, 117, 1748-1764. ${ }^{\text {h }}$ Arnold, D. R.; de P. Nicholas, A. M.; Young, K. M. Can. J . Chem. 1986, 64, 769-772. ' Birkhofer, H.; Beckhaus, H.-D.; Peters, K.; von Schnering, H. G.; Rüchardt, C. Chem. Ber. 1993, 126, 1693-1699. ${ }^{j}$ This work. k Reference 23b. ' Schüle, U. Ph.D. Thesis, University of Freiburg, 1992, ref 1. m Gleissner, R. Ph.D. Thesis, University of Freiburg, 1988, ref 16. n Pakusch, J .; Beckhaus, H.-D.; Rüchardt, C. Chem. Ber. 1991, 124, 1191-1198. Rausch, R. Ph.D. Thesis, University of Freiburg, 1984. Schulze, R.; Beckhaus, H.-D.; Rüchardt, C. J . Pract. Chem. 1990, 332, 325-330. ${ }^{\mathrm{P}}$ Geminal interactions in the saturated radical precursor are neglected. 9 Korth, H.-G.; Lommes, P.; Sustman, R.; Sylander, L.; Stella, L. New. J . Chem. 1987, 11, 365-375. r Nölke, M.; Verevkin, S. P.; Beckhaus, H.-D.; Rüchardt, C. Liebigs Ann. 1995, 41-51. s Brocks, J . J .; Welle, F. M.; Beckhaus, H.-D.; Rüchardt, C. in preparation. t Welle, F. M.; Verevkin, S. P.; Beckhaus, H.-D.; Rüchardt, C. Liebigs Ann. 1997, 155-163. " Schulze, R.; Beckhaus, H.-D.; Rüchardt, C. Chem. Ber. 1993, 126, 1031-1038. v Macl nnes, I.; Walton, J. C.; Nonhebel, D. C. J . Chem. Soc., Perkin Trans. 2 1987, 1789-1794. w Reference 1. x Welle, F.; Verevkin, S. P.; Keller, M.; Beckhaus, H.-D.; Rüchardt, C. Chem. Ber. 1994, 127, 697-710. y Herberg, C. Ph.D. Thesis, University of Freiburg, 1992. z Rakus, K.; Schätzer, J .; Verevkin, S. P.; Beckhaus, H.-D.; Rüchardt, C. Chem. Ber. 1994, 127, 1095-1103. aa Strain enthalpy is implied. bb Wurche, F. Diploma Thesis, University of Freiburg, 1996.

available from Rüchardt's kinetic and thermochemical studies. ${ }^{16}$ Also, a variety of theoretical approaches at various levels of theory, e.g., UHF or ROHF 4-31G, 21a Density Functional Theory, ${ }^{22 a}$ and MP4 methods, ${ }^{22 b}$ have been used to obtain values of $\mathrm{BDE}(\mathrm{C}-\mathrm{H})$.

ESR Hyperfine Coupling Constants. Many of the values of $\mathrm{a}\left(\mathrm{H}_{\alpha}\right)$ and of $\mathrm{a}\left(\mathrm{H}_{\beta} \mathrm{Me}\right)$ required for the present

(22) (a) J ursic, B. S.; Timberlake, J. W.; Engel, P. S. Tetrahedron Lett. 1996, 37, 6473-6474. (b) Leroy, G.; Sana, M.; Wilante, C. J . Mol. Struct. (Theochem.) 1991, 228, 37-45.

(23) (a) Berndt, A.; Fischer, H.; Paul, H. In Magnetic Properties of Free Radicals; Fischer, H., Hell wege, K.-H., Eds.; Landolt-Börnstein, Numerical Data and Functional Relationships in Science and Technology, New Series, Volume 9, Subvolume b; Springer-Verlag: Berlin, 1977. (b) Neugebauer, F. A. Magnetic Properties of Free Radicals; Fischer, H., Ed.; Landolt-Börnstein, Numerical Data and Functional Relationships in Science and Technology, New Series, Volume 17, Subvolume b; Springer-Verlag: Berlin, 1987. study were obtained from the literature. ${ }^{23}$ Although the spectra were recorded in a wide range of solvents, our analysis of more than 200 hyperfine splitting constants showed that the values of $a\left(H_{\alpha}\right)$ and $a\left(H_{\beta} M e\right)$ for any single radical vary within a range of $<0.3 \mathrm{G}$ if measured in different nonpolar solvents. Measurements in aqueous solutions show variations of up to $0.5 \mathrm{G}$ from those made in nonpolar solvents, while splittings obtained from sol id samples show much larger variability, and hence are not suitable.

Some values of $a\left(\mathrm{H}_{\alpha}\right)$ and $\mathrm{a}\left(\mathrm{H}_{\beta} \mathrm{Me}\right)$ in nonpolar solvents required for the present study were not available and were therefore measured in these laboratories. The radicals $3 \mathbf{a}, \mathbf{4 a}, \mathbf{9 a}, \mathbf{9 b}, \mathbf{1 0 a}, \mathbf{1 0 b}, \mathbf{1 2 a}, \mathbf{1 2 b}$, and $\mathbf{2 7}$ (the structures of radicals $\mathbf{1 - 2 3}$ are given in Table 1 ) were each generated in the cavity of the ESR spectrometer by 

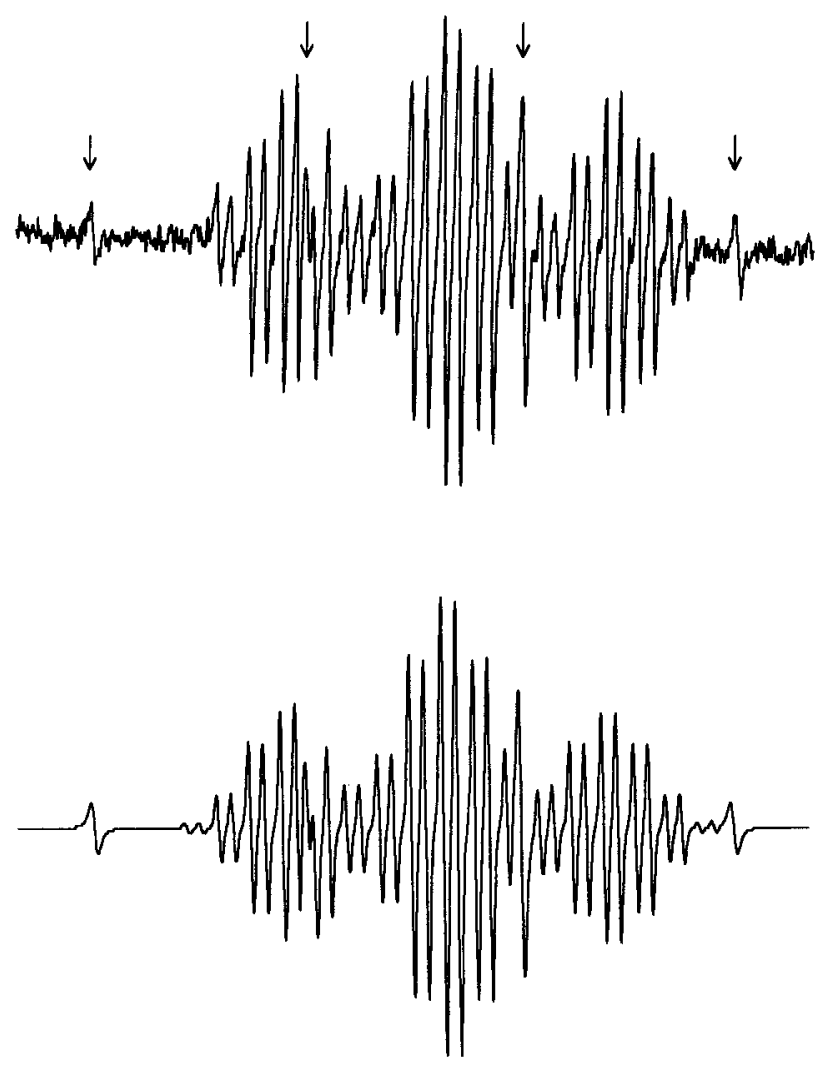

3284

3304

3324

3344

3364

Figure 1. ESR spectrum of radicals $\mathbf{2 5}$ and $\mathbf{9 a}$ and its simulation (below); the arrows indicate the quadruplet of $\mathbf{9 a}$.

UV irradiation of a solution of the corresponding $\mathrm{C}-\mathrm{H}$ compound and di-tert-butyl peroxide in a nonpolar solvent. Similar irradiation of a mixture of di-tert-butyl peroxide, triethylsilane (or hexamethylditin), and ethyl 2-bromopropionate afforded the I-(ethoxycarbonyl)ethyl radical $\mathbf{6} \mathbf{b}$ via abstraction of the bromine atom by $\mathrm{Et}_{3} \mathrm{Si}^{\cdot}$ or $\mathrm{Me}_{3} \mathrm{Sn}$ : The 9-methylfluoren-9-yl radical 18a was generated by thermal homolysis of the dimer in diphenyl ether. Malononitrile and methylmalononitrile, the chosen precursors for the radicals $10 \mathbf{a}$ and $\mathbf{1 0 b}$, were insufficiently soluble in nonpolar solvents to give suitable ESR spectra. However, satisfactory signals were obtained by irradiation of saturated solutions of the two precursors in a 1:1 mixture of benzene and di-tert-butyl peroxide, even though in the case of methylmal ononitrile a two-phase system was formed.

3-M ethyl-2,4-pentanedione, when irradiated in di-tertbutyl peroxide solution, gave a complex ESR signal comprised of two overlapping spectra (Figure 1). The major spectrum $(80 \%)$, a doublet $(\mathrm{a}(\mathrm{H})=1.46 \mathrm{G})$ of triplets $(\mathrm{a}(\mathrm{H})=16.25 \mathrm{G})$ of septets $(\mathrm{a}(\mathrm{H})=3.23 \mathrm{G})$, was tentatively assigned to the radical $\mathbf{2 5}$, while the minor component $(20 \%)$ was a quartet $(\mathrm{a}(\mathrm{H})=21.5 \mathrm{G})$ assigned to the radical $\mathbf{9 a}$.

We suggest that formation of $\mathbf{2 5}$ initially involves hydrogen-atom abstraction by the electrophilic $\mathrm{Bu}^{\mathrm{t}} \mathrm{O}^{*}$ radical from the 3-methyl substituent, the $\mathrm{C}-\mathrm{H}$ bonds of which are the least affected by the electron-withdrawing nature of the carbonyl groups. The $\beta$-proton in the species $\mathbf{2 4}$ so formed is more acidic than it is in the precursor because of the adjacent radical center. Hence $\mathbf{2 4}$ undergoes rapid enolization to form the symmetrical radical 25.

As the preferential formation of $\mathbf{2 5}$ could be reasonably attributed to polar effects, the experiment was repeated in the presence of the polarity reversal catalyst trimethylamine-borane complex. ${ }^{24}$ As expected, the intermediate nucleophilic $\mathrm{Me}_{3} \mathrm{~N} \cdot \mathrm{BH}_{2} \cdot$ radical abstracted hydrogen with high selectivity from the electrophilic 3-position of the precursor to afford only $\mathbf{9 a}$, the spectrum of which appeared as a clean quartet $(\mathrm{a}(\mathrm{H})=21.5 \mathrm{G})$, although the spectral simulation showed that it was necessary to include a very small septet coupling $(a(H)$ $=0.1 \mathrm{G}$ ) to account for the line width. The same method involving catalysis by $\mathrm{Me}_{3} \mathrm{~N} \cdot \mathrm{BH}_{3}$ was effective for generating the radical $\mathbf{9 b}$ from the parent dione.

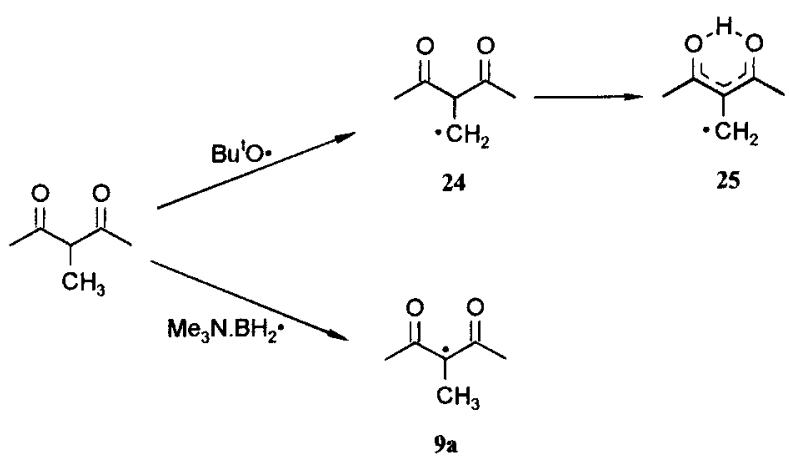

An attempt to form the radical $\mathbf{2 8}$ gave what appears to be another example of polar effects on hydrogen-atom abstraction. When the precursor 26 in di-tert-butyl peroxide was subjected to UV irradiation, the ESR spectrum with hfc's $\mathrm{a}(\mathrm{lH})=1.34 \mathrm{G}, \mathrm{a}(2 \mathrm{H})=14.30 \mathrm{G}$, $\mathrm{a}(3 \mathrm{H})=4.04 \mathrm{G}$, and $\mathrm{a}(\mathrm{IN})=7.00 \mathrm{G}$ was assigned to the radical 27. Apparently the selectivity of the reaction is affected not only by statistical factors but also by the preference of the electrophilic Buto radical for attack on the methyl $\mathrm{C}-\mathrm{H}$ bonds adjacent to the electron-donating nitrogen rather than on the 2-CH position, even though the latter would afford the more stabilized product $\mathbf{2 8}$.

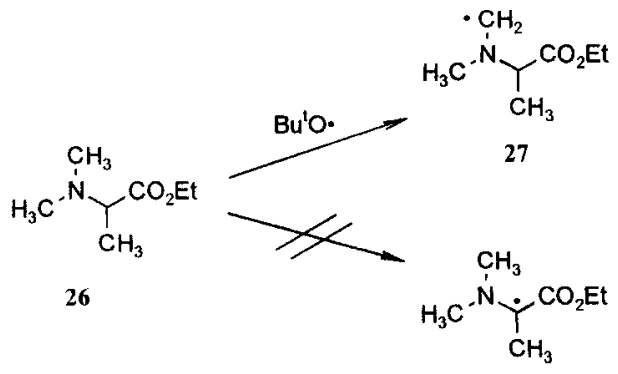

28

The hyperfine splitting constants of $\mathbf{9 a}, \mathbf{2 5}, \mathbf{2 7}$, and the other radicals generated in the course of this work were all determined by computer simulation.

Correlation of Radical Stabilization Enthalpy with $\mathbf{a}\left(\mathbf{H}_{\alpha}\right)$ and $\mathbf{a}\left(\mathbf{H}_{\beta} \mathbf{M e}\right)$. Table 1 gives a list of values of RSE for 40 radicals determined by the Rüchardt method from changes in the values of $B D E(C-C)$ by comparison with alkyl-substituted ethanes with the same

(24) Paul, V.; Roberts, B. P.; Willis, J . J . Chem. Soc., Perkin Trans 2 1989, 1953-1261. Paul, V.; Roberts, B. P. J . Chem. Soc., Chem. Commun. 1987, 1322-1324. 


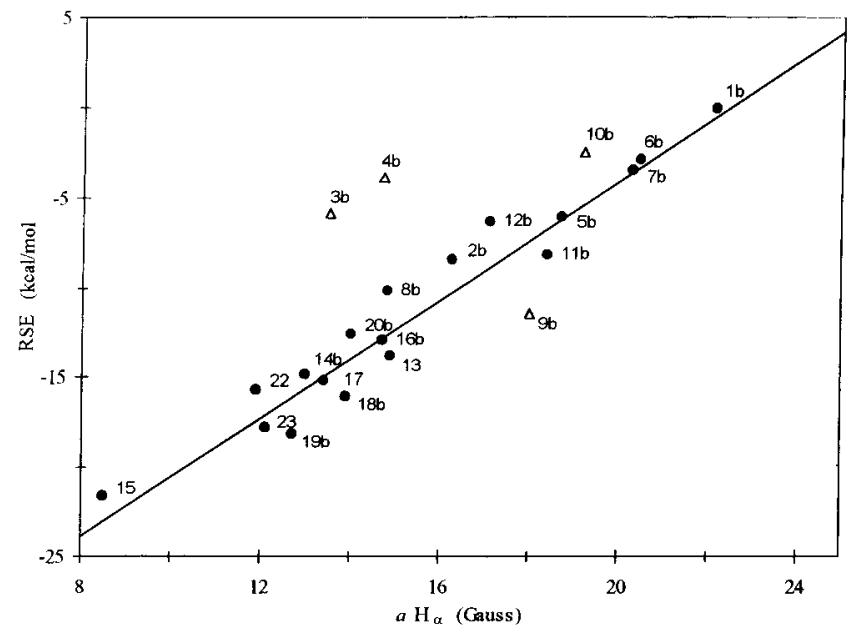

Figure 2. Plot of RSE against $\mathrm{a}\left(\mathrm{H}_{\alpha}\right)$ showing the line of eq 3 in Table 4: $(\triangle)$ outliers for the calculation of eq 3 . Compound numbers are shown in Table 1.

strain dissociation enthalpy. ${ }^{16}$ A consequence of this method is that all saturated acyclic tertiary and secondary radicals are defined as having RSE $=0$. Furthermore, similarly substituted radicals, whether secondary or tertiary, all have the same value of RSE, e.g., $\cdot{ }^{\circ} \mathrm{CR}^{1} \mathrm{R}^{2} \mathrm{COPh}$ and ${ }^{\circ} \mathrm{CHR}{ }^{3} \mathrm{COPh}$ have $\mathrm{RSE}=-6.0 \mathrm{kcal} / \mathrm{mol}$ no matter what the structures of the saturated alkyl substituents $R^{1}, R^{2}$, and $R^{3}$ are. Hence, the values of $R S E$ given in Table 1 are not necessarily those determined for the particular radical specified but are the mean values obtained for a number of radicals of the same type. However, to maintain consistency, ESR data are given only for those radicals in which the saturated alkyl substituent(s) is methyl. Also it should be noted that Table 1 differs from that in our earlier paper ${ }^{1}$ in that it contains RSE data for five new radicals $\mathbf{8}, \mathbf{1 2}, \mathbf{2 1}, \mathbf{2 2}$, and 23, improved values of RSE for radicals $\mathbf{9}$ and $\mathbf{1 0}$ corrected for strain in the precursor, and more recent ESR splitting constants determined in nonpolar solvents for most of the radicals listed.

A plot of a $\left(\mathrm{H}_{\alpha}\right)$ against RSE for all the appropriate (i.e., secondary) radicals in Table 1 is shown in Figure 2. Linear regression affords eq 3 (see Table 4) with coefficients very similar to those given in our earlier paper. Figure 2 shows that all the species studied lie reasonably close to the line of best fit except $\mathbf{3 b}\left({ }^{\circ} \mathrm{CHMeOBu}^{t}\right)$ and $\mathbf{4 b}\left(\cdot{ }^{\circ} \mathrm{CHMeNH}_{2}\right)$, the two radicals expected to be somewhat pyramidalized. Each has a value of $\mathrm{a}\left(\mathrm{H}_{\alpha}\right)$ about 5 $\mathrm{G}$ less than those estimated from eq 3.

Since in the Rüchardt method values of $\mathrm{BDE}(\mathrm{C}-\mathrm{H})$ are obtained by combination of values of RSE with thermochemical data for the parent hydrocarbon, a pl ot of a $\left(\mathrm{H}_{\alpha}\right)$ against $\mathrm{BDE}(\mathrm{C}-\mathrm{H})$ should also give a similar linear correlation. Equation 5, obtained by linear regression of the appropriate data in Table 1, shows the standard deviation to be much the same as those for eq 3 . Once again the two nonplanar radicals $\mathbf{3 b}$ and $\mathbf{4 b}$ are outliers.

We suggested above that $\mathrm{a}\left(\mathrm{H}_{\beta} \mathrm{Me}\right)$ might be a better indicator of RSE and BDE $(\mathrm{C}-\mathrm{H})$ than $\mathrm{a}\left(\mathrm{H}_{\alpha}\right)$ because the former is less sensitive than the latter to deviations from planarity of the radical center. ${ }^{4}$ The plot of $\mathrm{a}\left(\mathrm{H}_{\beta} \mathrm{Me}\right)$ for tertiary radicals against RSE (Figure 3 ) shows the validity of this hypothesis. The data point for the oxygensubstituted radical ${ }^{\circ} \mathrm{CMe}_{2} \mathrm{OPr}^{i}$ 3a lies very close to the line of best fit (eq 4 in Table 4) while that for the amino-
Table 2. BDE (C-H) for $\mathrm{H}-\mathrm{CHXY}$ Determined by the Bordwell Method and $\mathrm{a}\left(\mathrm{H}_{\alpha}\right)$ for the Corresponding Radicals

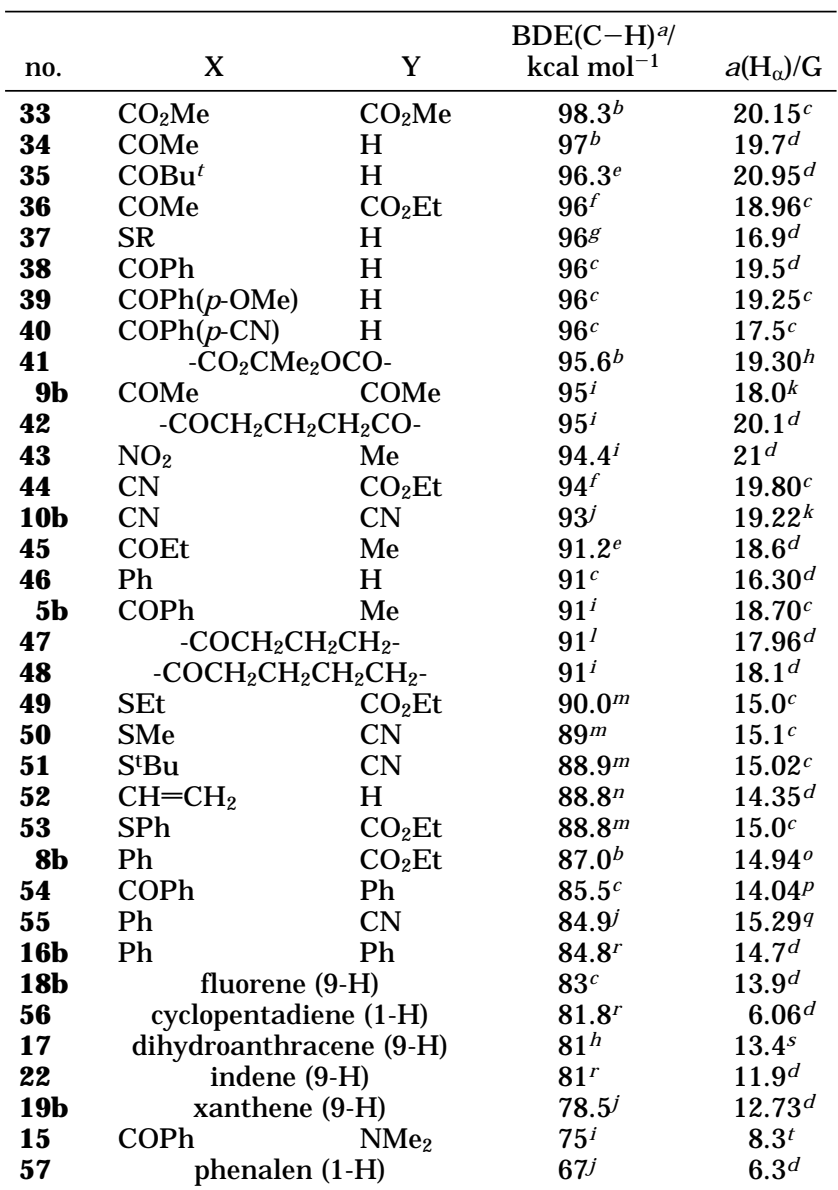

a The $\operatorname{BDE}(\mathrm{C}-\mathrm{H})$ data in this table is $3.0 \mathrm{kcal} / \mathrm{mol}$ higher than given in the original literature (see text). ${ }^{b}$ Reference $20 \mathrm{~b}$. ${ }^{c}$ Reference 23b. ${ }^{d}$ Reference 23a. ${ }^{e}$ Reference $20 \mathrm{~d}$. ${ }^{f}$ Reference $20 \mathrm{c}$. ${ }^{g}$ Reference 20b. ${ }^{h}$ Kaushal, P.; Pearl, L. H.; Roberts, B. P. J . Chem. Soc., Perkin Trans. 2 1990, 1663-1670. ' Reference 20e. j Reference 20j. ${ }^{k}$ This work. ' Reference 20f. $m$ Reference $20 \mathrm{~g} .{ }^{n}$ Reference 20i. ${ }^{\circ}$ Korth, H.-G.; Lommes, P.; Sustman, R.; Sylander, L.; Stella, L. New. J . Chem. 1987, 11, 365-375. ${ }^{\mathrm{P}}$ Paul, H.; Fischer, H. Helv. Chim. Acta 1973, 56, 1575-1588. 9 Korth, H.-G.; Lommes, P.; Sicking, W.; Sustmann, R. Chem. Ber. 1985, 118, 4627-4631. $r$ Reference 20h. ${ }^{s}$ Herberg, C. Ph.D. Thesis, University of Freiburg, 1992. ${ }^{t}$ Welle, F.; Verevkin, S. P.;Keller, M.; Beckhaus, H.-D.; Rüchardt, C. Chem. Ber. 1994, 127, 697-710.

Table 3. BDE (MeXYC-H) Determined by the Bordwell Method and $\mathrm{a}\left(\mathrm{H}_{\beta}{ }^{\mathrm{Me}}\right)$ for the Corresponding Radicals

\begin{tabular}{|c|c|c|c|c|}
\hline no. & $\mathrm{x}$ & $Y$ & $\begin{array}{c}\mathrm{BDE}(\mathrm{C}-\mathrm{H})^{\mathrm{a}} / \\
\mathrm{kcal} \mathrm{mol}^{-1}\end{array}$ & $\mathrm{a}\left(\mathrm{H}_{\beta}{ }^{\mathrm{Me}}\right) / \mathrm{G}$ \\
\hline 43 & $\mathrm{NO}_{2}$ & $\mathrm{H}$ & $94.4^{b}$ & $25^{c}$ \\
\hline 45 & coEt & $\mathrm{H}$ & $91.2^{\mathrm{d}}$ & $22.5^{c}$ \\
\hline $5 b$ & COPh & $\mathrm{H}$ & $91^{b}$ & $21.86^{e}$ \\
\hline 58 & & OCO- & $90.5^{f}$ & $22.8^{e}$ \\
\hline 59 & $\mathrm{NO}_{2}$ & $\mathrm{Me}$ & $89.8^{b}$ & $19.8^{\mathrm{c}}$ \\
\hline $5 \mathbf{a}$ & COPh & $\mathrm{Me}$ & $89^{b}$ & $19.13^{e}$ \\
\hline 60 & COPri & $\mathrm{Me}$ & $87^{b}$ & $19.9 c$ \\
\hline 21 & pentan & lopentadiene & $80^{g}$ & $6.4^{c}$ \\
\hline $18 \mathbf{a}$ & & uorene & $78.4^{\mathrm{h}}$ & $14.56^{i}$ \\
\hline
\end{tabular}

a The BDE $(\mathrm{C}-\mathrm{H})$ data in this table are $3.0 \mathrm{kcal} / \mathrm{mol}$ higher than given in the original literature. See text. b Reference 20e. c Reference 23a. ${ }^{d}$ Reference $20 \mathrm{~d}$. ${ }^{e}$ Reference $23 \mathrm{~b} .{ }^{f}$ Reference $20 \mathrm{k}$. 9 Reference 20i. h Reference 20g. i This work.

substituted radical ${ }^{\circ} \mathrm{CMe}_{2} \mathrm{NH}_{2} \mathbf{4 a}$ is much closer than it is in the plot of Figure 2. However, as Figure 3 shows, there are serious discrepancies for the ${ }^{\circ} \mathrm{CMe}(\mathrm{COMe})_{2}$ 
Table 4. Linear Correlations of RSE and BDE(CH) with ESR Parameters

\begin{tabular}{|c|c|c|c|c|}
\hline eq & data collectiona & linear correlations $/ \mathrm{kcal}^{\mathrm{mol}}{ }^{-1}$ & $r^{c}$ & $\mathrm{n}^{\mathrm{d}}$ \\
\hline 3 & Rüchardt & $\mathrm{RSE}^{\mathrm{sec}}=1.65 \mathrm{a}\left(\mathrm{H}_{\alpha}\right)-37.1( \pm 1.3)^{\mathrm{e}}$ & 0.97 & 18 \\
\hline 4 & Rüchardt & $\operatorname{RSE}^{\mathrm{t}}=1.61 \mathrm{a}\left(\mathrm{H}_{\beta}^{\mathrm{Me}}\right)-36.8( \pm 1.4)^{\mathrm{f}}$ & 0.97 & 13 \\
\hline 5 & Rüchardt & $\operatorname{BDE}(\mathrm{C}-\mathrm{H})=1.61 \mathrm{a}\left(\mathrm{H}_{\alpha}\right)+62.4( \pm 1.6)$ & 0.96 & 18 \\
\hline 6 & Rüchardt & $\mathrm{BDE}(\mathrm{C}-\mathrm{H})=1.58 \mathrm{a}\left(\mathrm{H}_{\beta}^{\mathrm{Me}}\right)+59.4( \pm 1.3)$ & 0.97 & 13 \\
\hline 7 & Bordwell & $\mathrm{BDE}(\mathrm{C}-\mathrm{H})=1.93 \mathrm{a}\left(\mathrm{H}_{\alpha}\right)+57.8( \pm 2.3)$ & 0.95 & 33 \\
\hline 8 & Bordwell & $\mathrm{BDE}(\mathrm{C}-\mathrm{H})=1.45 \mathrm{a}\left(\mathrm{H}_{\beta}^{\mathrm{Me}}\right)+59.4( \pm 1.7)$ & 0.95 & 8 \\
\hline 9 & McMillen/Golden & $\mathrm{BDE}(\mathrm{C}-\mathrm{H})=1.57 \mathrm{a}\left(\mathrm{H}_{\alpha}\right)+65.2( \pm 3.2)$ & 0.93 & 22 \\
\hline 10 & McMillen/Golden & $\operatorname{BDE}(\mathrm{C}-\mathrm{H})=1.45 \mathrm{a}\left(\mathrm{H}_{\beta}^{\mathrm{Me}}\right)+62.8( \pm 1.4)$ & 0.98 & 9 \\
\hline 11 & Tsang & $\mathrm{BDE}(\mathrm{C}-\mathrm{H})=1.92 \mathrm{a}\left(\mathrm{H}_{\alpha}\right)+57.8( \pm 1.0)$ & 0.96 & 8 \\
\hline 12 & Tsang & $\mathrm{BDE}(\mathrm{C}-\mathrm{H})=1.21 \mathrm{a}\left(\mathrm{H}_{\beta}^{\mathrm{Me}}\right)+68.5( \pm 0.3)^{\mathrm{g}}$ & 0.99 & 5 \\
\hline 13 & Pasto & $\operatorname{BDE}(\mathrm{C}-\mathrm{H})=1.68 \mathrm{a}\left(\mathrm{H}_{\alpha}\right)+64.7( \pm 1.8)$ & 0.95 & 16 \\
\hline 14 & Timberlake & $\operatorname{BDE}(\mathrm{C}-\mathrm{H})=1.90 \mathrm{a}\left(\mathrm{H}_{\alpha}\right)+55.1( \pm 3.0)$ & 0.93 & 5 \\
\hline
\end{tabular}

a For citations see text. ${ }^{b} a\left(H_{\alpha}\right)$ and $a\left(H_{\beta}\right.$ Me) in $\mathrm{G}$. c Correlation coefficient. d Number of data points. e Only valid for secondary radicals. ${ }^{f}$ Only valid for tertiary radicals. 9 The maximum deviation $(0.3 \mathrm{kcal} / \mathrm{mol})$ is smaller than the biggest error estimated by Tsang $(0.7 \mathrm{kcal} /$ mol) in ref 19.

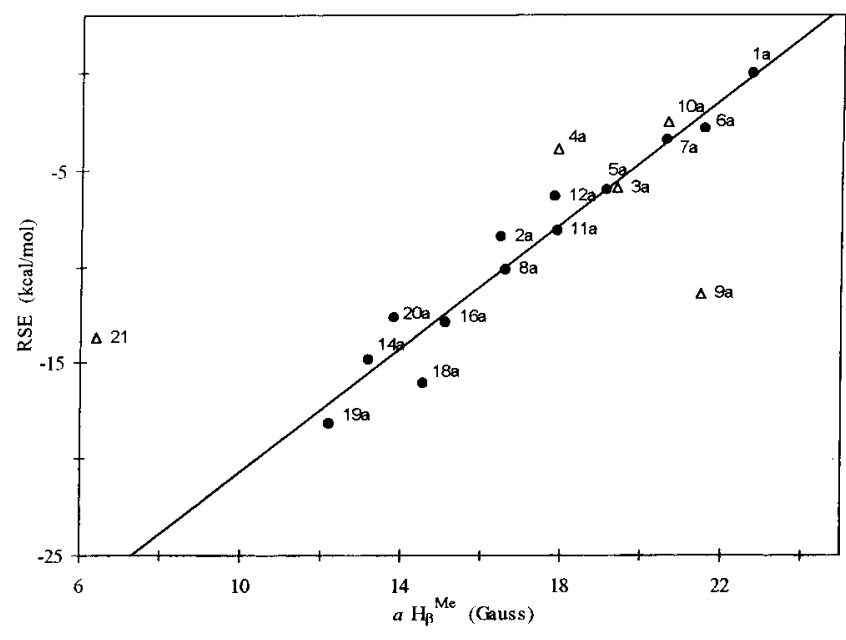

Figure 3. Plot of RSE against $\mathrm{a}\left(\mathrm{H}_{\beta} \mathrm{Me}\right)$ for tertiary radicals showing the line of eq 4 in Table 4: $(\triangle)$ outliers for the calculation of eq 4. Compound numbers are shown in Table 1.

radical $9 \mathrm{a}$ and the pentamethyl cyclopentadienyl radical 21 which have a values of a $\left(\mathrm{H}_{\beta} \mathrm{Me}\right)$ about $6 \mathrm{G}$ higher and $8 \mathrm{G}$ lower than that expected from eq 4 . The case of radical 9 a is discussed below. The anomal ous behavior of $\mathbf{2 1}$ arises from the orbital degeneracy of the cyclopentadienyl radical. ${ }^{25}$ It is noteworthy that when the degeneracy is broken by monoalkyl substitution, the value of $\mathrm{a}\left(\mathrm{H}_{\beta} \mathrm{Me}\right)$ is aproximately doubled. Thus the methylcyclopentadienyl radical has $\mathrm{a}\left(\mathrm{H}_{\beta} \mathrm{Me}\right)=12.7 \mathrm{G}^{26 a}$ or $14.8 \mathrm{G} .{ }^{26 \mathrm{~b}}$ The latter value would place $\mathbf{2 1}$ very close to the line of eq 4 in Figure 3.

A pleasing feature of Figure 3 is that the data for a wide variety of radicals including captodative radicals, e.g., 14a, unsaturated species, e.g., 20a, and numerous substituted alkyl radicals lie close to the line of best fit over a range of $18 \mathrm{kcal} / \mathrm{mol}$. This engenders confidence both in the validity of the correlations and in the reliability of the experimental data.

In the Rüchardt method, each secondary radical ${ }^{\circ} \mathrm{CHXY}$ has the same value of RSE as the corresponding tertiary radical ${ }^{\circ} \mathrm{CM}$ eXY. However, the values of $\mathrm{a}\left(\mathrm{H}_{\beta} \mathrm{Me}\right)$ for the latter are always smaller than those for the former. Consequently eq 4 must be modified for secondary

(25) For a discussion of the orbital degeneracy of cyclopentadienyl radical, see ref 26 .

(26) (a) Kira, M.; Watanabe, M.; Sakurai, H. J . Am. Chem. Soc. 1980 102, 5202. (b) Barker, P. J .; Davies, A. G.; Tse, M.-W. J . Chem. Soc. Perkin Trans. 2 1980, 941-948.

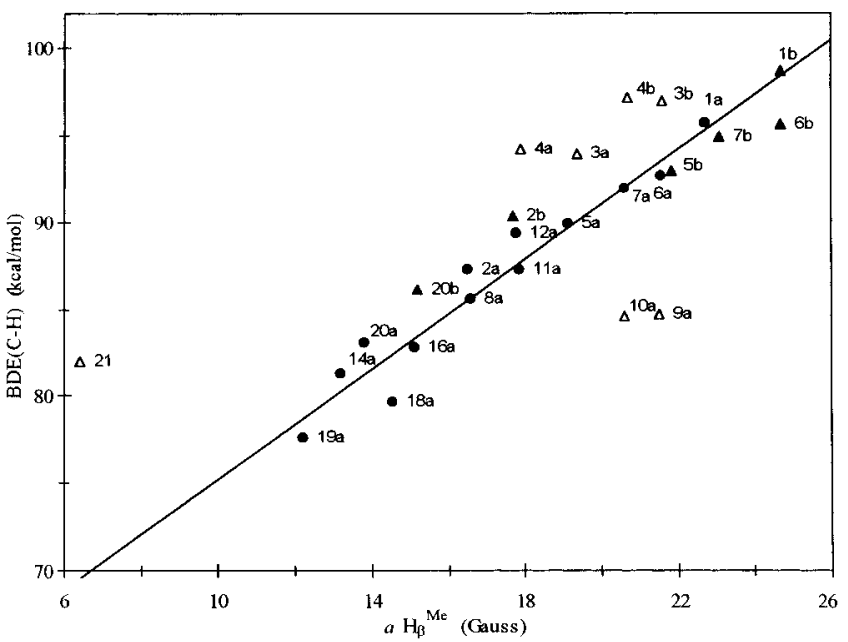

Figure 4. Plot of $B D E(C-H)$ against $a\left(H_{\beta} M e\right)$ showing the line of eq 6: $(\triangle)$ outliers; (s) secondary radicals; $(\bullet)$ tertiary radicals. Only the tertiary radicals were used to calculate eq 6 in Table 4. Compound numbers are shown in Table 1.

radicals of the type $\cdot \mathrm{CHMeX}$. Unfortunately there are not sufficient data available to enable a reliable correlation to be established. However, the relationship RSE ${ }^{\mathrm{sec}}$ $=1.17 \mathrm{a}\left(\mathrm{H}_{\beta} \mathrm{Me}\right)-30.4$ gives satisfactory agreement with all the data available.

The correlation (Figure 4) of $\mathrm{a}\left(\mathrm{H}_{\beta} \mathrm{Me}\right)$ against Rüchardt's values of $\mathrm{BDE}(\mathrm{C}-\mathrm{H})$ (eq 6$)$ is somewhat less satisfactory than that against RSE (eq 4) although better than it is for the correlation of $\mathrm{a}\left(\mathrm{H}_{\alpha}\right)$ with $\operatorname{BDE}(\mathrm{C}-\mathrm{H})$ (eq 5). The nonplanar radicals $\mathbf{3 a}, \mathbf{3} \mathbf{b}, \mathbf{4 a}$, and $\mathbf{4} \mathbf{b}$, the dicyano and the diacyl radicals $9 \mathbf{a}$ and $\mathbf{1 0 a}$, and the pentamethylcycl opentadienyl radical $\mathbf{2 1}$ all lie off the line of eq 6 . There is considerable divergence between the values of $\mathrm{BDE}(\mathrm{C}-\mathrm{H})$ for $\mathbf{9 b}$ and $\mathbf{1 0 b}$ obtained from Rüchardt's data ( 87.7 and $87.6 \mathrm{kcal} / \mathrm{mol}$, respectively) and those obtained by Bordwell's method $(95$ and $93 \mathrm{kcal} / \mathrm{mol}$, respectively). The fact that the latter values lie close to the line of best fit (eq 7) in Figure 5 suggests that the former require reevaluation. It is noteworthy that for values of $B D E(C-H)$, unlike those of RSE, the same correlation (eq 6) applies to both secondary and tertiary radicals.

We examined next the correlation of $\mathrm{a}\left(\mathrm{H}_{\alpha}\right)$ and $\mathrm{a}\left(\mathrm{H}_{\beta} \mathrm{Me}\right)$ with $\mathrm{BDE}(\mathrm{C}-\mathrm{H})$ determined by Bordwell's cyclovoltametry/acidity function method. ${ }^{20}$ These data were originally calibrated by reference to a scale of 15 values of $\mathrm{BDE}(\mathrm{C}-\mathrm{H})$ measured in the gas phase. ${ }^{20 \mathrm{j}}$ However, the 


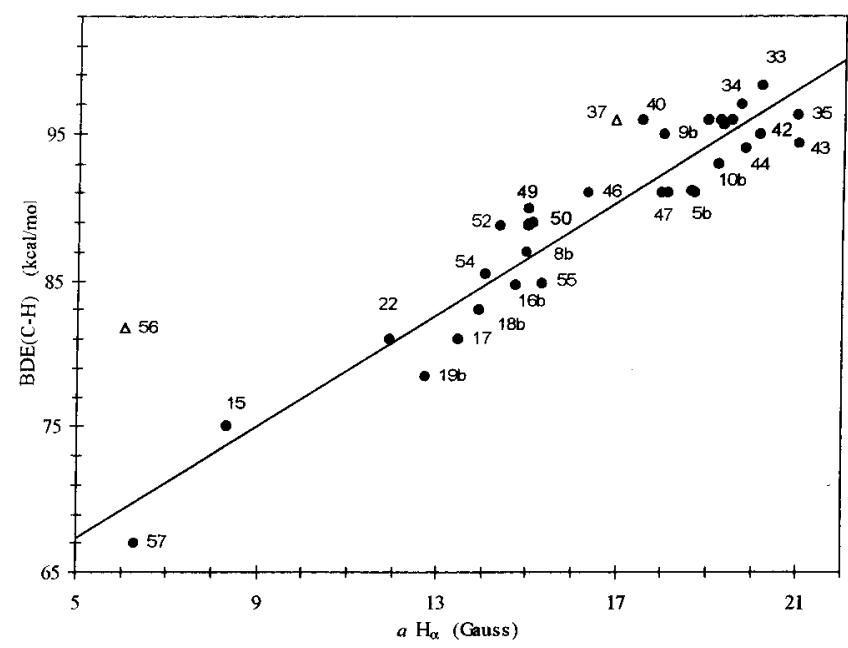

Figure 5. Plot of Bordwell's values of $\operatorname{BDE}(\mathrm{C}-\mathrm{H})$ against $\mathrm{a}\left(\mathrm{H}_{\alpha}\right)$ showing the line of eq 7 in Table 4: $(\Delta)$ outliers. Compound numbers are shown in Tables 1 and 2.

gas-phase data were in turn based on values for the isopropyl and ethyl radical ${ }^{18}$ that have been shown by more recent work to be too low. ${ }^{19}$ Accordingly, for the present study the Bordwell values of $\mathrm{BDE}(\mathrm{C}-\mathrm{H})$ have each been increased by $3.0 \mathrm{kcal} / \mathrm{mol}$.

Tables 2 and 3 show the data for 44 radicals bearing various combinations of the substituents $\mathrm{COR}, \mathrm{CO}_{2} \mathrm{R}, \mathrm{SR}$, $\mathrm{NO}_{2}, \mathrm{CN}$, and $\mathrm{NR}_{2}$ as well as for a variety of unsaturated radicals. A plot (Figure 5$)$ of $a\left(\mathrm{H}_{\alpha}\right)$ against $\mathrm{BDE}(\mathrm{C}-\mathrm{H})$ for 35 radicals shows a reasonably good linear correlation expressed by eq 7, the most serious anomaly being the cyclopentadienyl radical $\mathbf{5 9}$ which, as discussed above, has a value of $\mathrm{a}\left(\mathrm{H}_{\alpha}\right)$ about $6 \mathrm{G}$ less than that expected. The sulfur-substituted radical, ${ }^{\circ} \mathrm{CH}_{2} \mathrm{SR} \mathbf{3 7}$, has an a $\left(\mathrm{H}_{\alpha}\right)$ about $3 \mathrm{G}$ less than that calculated from eq 7, but the value of $\operatorname{BDE}(\mathrm{C}-\mathrm{H})$ for this radical is open to doubt because it was derived from an estimate of the acidity of the parent compound.

For the nine radicals for which appropriate data are available, there is a good linear correlation of $\mathrm{a}\left(\mathrm{H}_{\beta} \mathrm{Me}\right)$ with Bordwell's BDE $(\mathrm{C}-\mathrm{H})$ expressed by eq 8 , the only serious anomaly being the pentamethylcycl opentadienyl radical 21 which has a $\left(\mathrm{H}_{\beta} \mathrm{Me}\right)$ about $8 \mathrm{kcal} / \mathrm{mol}$ lower than that calculated (Figure 6).

An extensive set of data is available in the review by McMillen and Golden. ${ }^{18}$ Not surprisingly, in view of the wide range of sources, there is considerable scatter in a plot of $a\left(H_{\alpha}\right)$ against BDE $(\mathrm{C}-\mathrm{H})$. The line of best fit is given by eq 9 . A feature of this correlation is that the values of $\mathrm{a}\left(\mathrm{H}_{\alpha}\right)$ for methyl and some of the primary radicals deviate considerably from those calculated. The same is true of a plot of Tsang's best values of BDE (C $H)^{19}$ against $\mathrm{a}\left(\mathrm{H}_{\alpha}\right)$ (eq 11 ). However, in both cases the linear correlation is much better for the lesser number of data available for plots of $\mathrm{BDE}(\mathrm{C}-\mathrm{H})$ against $\mathrm{a}\left(\mathrm{H}_{\beta} \mathrm{Me}\right)$ (eqs 10 and 12).

Finally, we examined the correlation of $a\left(\mathrm{H}_{\alpha}\right)$ against values of $\mathrm{BDE}(\mathrm{C}-\mathrm{H})$ obtained by theoretical methods by Pasto $^{21}$ and Timberlake ${ }^{22 a}$ and their co-workers. In both cases rather poor linear correlations were observed, with data for radicals expected to be nonplanar lying well away from the lines of best fit (eqs 13 and 14). The theoretical values of $\mathrm{BDE}(\mathrm{C}-\mathrm{H})$ reported by Leroy et al. ${ }^{22 b}$ did not show a linear correlation with $\mathrm{a}\left(\mathrm{H}_{\alpha}\right)$.

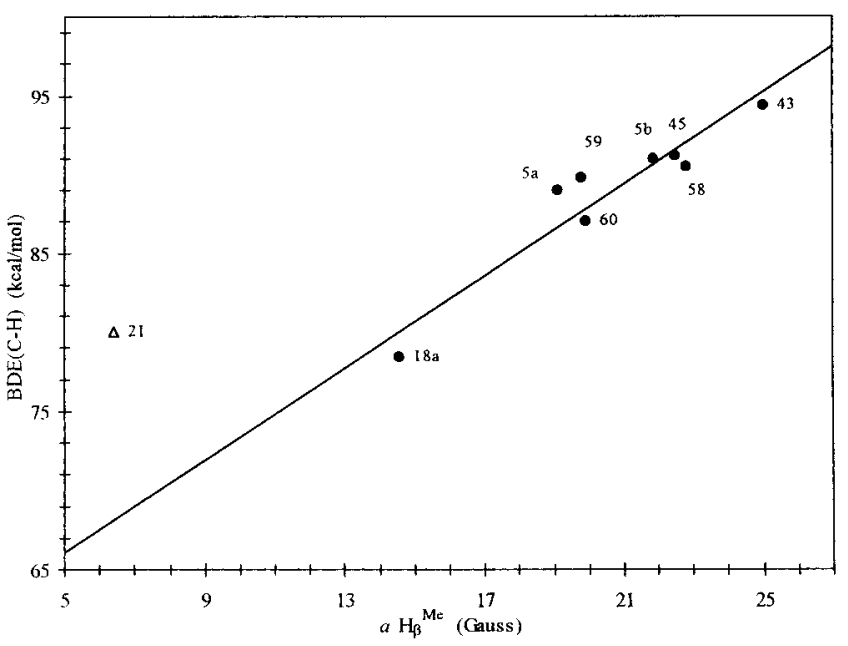

Figure 6. Plot of $B D E(C-H)$ against $\mathrm{a}\left(\mathrm{H}_{\beta} \mathrm{Me}\right)$ showing the line of eq 8 in Table 4: $(\triangle)$ outlier. Compound numbers are shown in Tables 1 and 3.

Prediction of RSE and BDE (C-H) from ESR Data. The results described above indicate that appropriate ESR hyperfine splitting constants correlate well with RSE's determined by the Rüchardt method which are useful indices of radical stability. Except for nonplanar radicals, e.g., ${ }^{\circ} C R^{1} R^{2} N^{3}{ }_{2}$, and the radicals $9 a$ or 21, the special features of which are discussed above, they are predictable from values of $\mathrm{a}\left(\mathrm{H}_{\alpha}\right)$ or $\mathrm{a}\left(\mathrm{H}_{\beta} \mathrm{Me}\right)$ by eqs 3 and 4 with the latter generally giving somewhat more accurate results. The correlations cover a range of about $22 \mathrm{kcal} / \mathrm{mol}$ and appear to be particularly suitable for estimating the RSE's of captodative and benzylic radicals. For all such radicals, values of RSE predicted from eqs 3 or 4 should be accurate to within $2.0 \mathrm{kcal} / \mathrm{mol}$. For radicals containing an $\alpha$-methyl substituent, eq 4 is preferred.

The prediction of the $\mathrm{C}-\mathrm{H}$ bond dissociation enthal pies of the parent compounds, which are widely used as indices of radical stability and reactivity, is more problematic. Values of BDE $(\mathrm{C}-\mathrm{H})$ calculated from $\mathrm{a}\left(\mathrm{H}_{\alpha}\right)$ by eqs $5,7,9$, and 11 are all in reasonable agreement, but eqs 13 and 14 based respectively on theoretical approaches give higher and lower values of $\mathrm{BDE}(\mathrm{C}-\mathrm{H})$. Values obtained from eq 9 are uniformly ca. $2.0 \mathrm{kcal} / \mathrm{mol}$ above those derived from eq 5 , while those calculated from eq 7 (and eq 11) show a slightly larger divergence at the top of the range $(>22 \mathrm{G}$ ) but coincide at about 24.5 G. We consider that either eq 5 based on Rüchardt's data ${ }^{16}$ or eq 7 based on Bordwell's data ${ }^{20}$ can confidently be used to obtain reliable values of $\mathrm{BDE}(\mathrm{C}-\mathrm{H})$ for planar or very nearly planar radicals to within a range of $2 \mathrm{kcal} /$ mol.

Reasonably consistent values of $\mathrm{BDE}(\mathrm{C}-\mathrm{H})$ can be obtained by substitution of the appropriate $\mathrm{a}\left(\mathrm{H}_{\beta} \mathrm{Me}\right)$ into eqs 6,8 , and 10 but eq 12 gives markedly higher values at the lower end of the scale. Equations 6 and 8 based respectively on Rüchardt's and Bordwell's results ${ }^{16,20}$ are derived from the widest range of experimental data, but values of $\mathrm{BDE}(\mathrm{C}-\mathrm{H})$ calculated from eq 8 tend to be about $2.0-2.5 \mathrm{kcal} / \mathrm{mol}$ lower than those obtained from eq 6, probably because of systematic differences in the experimental data. Since $\mathrm{a}\left(\mathrm{H}_{\beta} \mathrm{Me}\right)$ is less sensitive than $\mathrm{a}\left(\mathrm{H}_{\alpha}\right)$ to nonplanarity of the radical center, eq 6 is to be preferred over eq 5 if the appropriate ESR hyperfine coupling constants are available. 
Table 5. Pyramidalization Quotients for Radicals CHMeX

\begin{tabular}{lccc}
\hline \multicolumn{1}{c}{$\mathrm{X}$} & $\mathrm{a}\left(\mathrm{H}_{\alpha}\right) / \mathrm{G}$ & $\mathrm{a}\left(\mathrm{H}_{\left.\beta^{\mathrm{Me}}\right) / G}\right.$ & $\mathrm{Psec}$ \\
\hline $\mathrm{NH}_{2}$ & $14.7^{\mathrm{b}}$ & $20.7^{\mathrm{b}}$ & 1.41 \\
$\mathrm{NH}_{3}{ }^{+}$ & $22.7^{\mathrm{a}}$ & $26.7^{\mathrm{a}}$ & 1.18 \\
$\mathrm{NHCOCH}_{3}$ & $18.9^{\mathrm{b}}$ & $21.8^{\mathrm{b}}$ & 1.15 \\
$\mathrm{NHCONH}_{2}$ & $16.9^{\mathrm{b}}$ & $21.9^{\mathrm{b}}$ & 1.30 \\
$\mathrm{NHEt}_{\mathrm{NH}} \mathrm{Et}{ }^{+}$ & $14.6^{\mathrm{a}}$ & $20.0^{\mathrm{a}}$ & 1.37 \\
$\mathrm{NEtCHO}_{\mathrm{OEt}}$ & $22.6^{\mathrm{a}}$ & $26.9^{\mathrm{a}}$ & 1.19 \\
$\mathrm{OCOCH}$ & $18.8^{\mathrm{a}}$ & $22.0^{\mathrm{a}}$ & 1.17 \\
$\mathrm{OCHO}$ & $13.9^{\mathrm{b}}$ & $21.6^{\mathrm{b}}$ & 1.55 \\
$\mathrm{OP}(\mathrm{OEt})_{2}$ & $18.8^{\mathrm{a}}$ & $24.0^{\mathrm{a}}$ & 1.28 \\
$\mathrm{OPO}(\mathrm{OEt})_{2}$ & $19.6^{\mathrm{a}}$ & $24.5^{\mathrm{a}}$ & 1.25 \\
$\mathrm{OCONH}$ & $16.5^{\mathrm{a}}$ & $22.3^{\mathrm{a}}$ & 1.35 \\
$\mathrm{OCO}$ & $18.1^{\mathrm{a}}$ & $22.6^{\mathrm{a}}$ & 1.26 \\
$\mathrm{SEt}$ & $17.6^{\mathrm{a}}$ & $24.0^{\mathrm{a}}$ & 1.36 \\
$\mathrm{~S}(\mathrm{O}) \mathrm{Et}$ & $18.9^{\mathrm{a}}$ & $23.9^{\mathrm{a}}$ & 1.26 \\
$\left.\mathrm{~S}(\mathrm{O})_{2}\right) \mathrm{Et}$ & $16.5^{\mathrm{a}}$ & $20.3^{\mathrm{a}}$ & 1.23 \\
$\mathrm{Br}$ & $20.2^{\mathrm{a}}$ & $25.3^{\mathrm{a}}$ & 1.25 \\
$\mathrm{~F}$ & $21.6^{\mathrm{c}}$ & $27.3^{\mathrm{c}}$ & 1.26 \\
$\mathrm{O}$ & $20.5^{\mathrm{a}}$ & $24.7^{\mathrm{a}}$ & 1.20 \\
& $17.3^{\mathrm{a}}$ & $24.5^{\mathrm{a}}$ & 1.42
\end{tabular}

a Reference 23b. ${ }^{b}$ Reference 23b. c Carton, P. M.; Gilbert, B. C.; Laue, H. A. H.; Norman, R. O. C.; Sealy, R. C. J . Chem. Soc., Perkin Trans. 2 1975, 1245.

Although the satisfactory correspondence between the correlations based on experimental data suggest that values of $\mathrm{a}\left(\mathrm{H}_{\alpha}\right)$ and $\mathrm{a}\left(\mathrm{H}_{\beta} \mathrm{Me}\right)$ should be suitable for the prediction of $\mathrm{BDE}(\mathrm{C}-\mathrm{H})$, the plots in Figures 4-6 show that this is not valid for all radicals. The question arises, therefore, of how one might assess whether values of $\mathrm{BDE}(\mathrm{C}-\mathrm{H})$ obtained in this way are likely to be accurate. The radicals that deviate most from values predicted by the appropriate equations are simple saturated hydrocarbon radicals, radicals that may have unusual strain or dipolar effects, e.g., 9a, cyclic del ocalized radicals, e.g., 21, and radicals that are nonplanar. The first group presents no problem as accurate experimental values of $\mathrm{BDE}(\mathrm{C}-\mathrm{H})$ are al ready available. As the experimental data for some of the radicals in the second group, e.g., 9a, are in discord, the accurate prediction of $\operatorname{BDE}(\mathrm{C}-\mathrm{H})$ for such species must await agreement on correct values of $\mathrm{BDE}(\mathrm{C}-\mathrm{H})$. For the last group (nonplanar radicals), since values of $a\left(H_{\alpha}\right)$ are much more sensitive to pyrimidalization than are values of $\mathrm{a}\left(\mathrm{H}_{\beta} \mathrm{Me}\right)$, we suggest that the ratio $\mathrm{a}\left(\mathrm{H}_{\beta} \mathrm{Me}\right) / \mathrm{a}\left(\mathrm{H}_{\alpha}\right)$ be used as an index of deviation from planarity. ${ }^{27}$ Table 1 gives values of pyramidalization quotients $\mathrm{P}$ defined as

$$
\begin{aligned}
\mathrm{P}^{\mathrm{t}} & =\mathrm{a}\left(\mathrm{H}_{\beta} \mathrm{Me}\left({ }^{\circ} \mathrm{CMeXY}\right)\right) / \mathrm{a}\left(\mathrm{H}_{\alpha}\left({ }^{\circ} \mathrm{CHXY}\right)\right) \\
\mathrm{P}^{\mathrm{sec}} & =\mathrm{a}\left(\mathrm{H}_{\beta} \mathrm{Me}\left({ }^{\circ} \mathrm{CHXMe}\right)\right) / \mathrm{a}\left(\mathrm{H}_{\alpha}\left({ }^{\circ} \mathrm{CHXMe}\right)\right)
\end{aligned}
$$

where $X$ and $Y$ are any substituents. Further values of $\mathrm{P}^{\mathrm{sec}}$ obtained from literature data are shown in Table 5. Our survey of the data presented in the figures and tables indicates that if $\mathrm{P}^{\mathrm{t}}<1.05$ or if $\mathrm{P}^{\mathrm{sec}}<1.25$, then values of RSE and BDE should be obtainable from ESR data. We recommend that for this purpose eqs 3- 6 be used, with preference given to eqs 4 and 6 since $a\left(H_{\beta} M e\right)$ is less sensitive to pyramidalization of the radical center than is $a\left(H_{\alpha}\right)$. For radicals that meet the criteria, the calculated values of RSE and $\mathrm{BDE}(\mathrm{C}-\mathrm{H})$ should be accurate to within about $2.0 \mathrm{kcal} / \mathrm{mol}$.

In general the values of $\mathrm{P}^{\mathrm{t}}$ and $\mathrm{P}^{\mathrm{sec}}$ listed in Tables 1 and 5 confirm that a wide range of substituted secondary

(27) F or the first suggested use of this ratio as a measure of radical pyrimidalization, see ref 4 . and tertiary radicals including unsaturated radicals, benzylic radicals, radicals bearing a single electronwithdrawing substituent, and a large number of captodative species are either planar or sufficiently close to planar to allow values of $\operatorname{BDE}(\mathrm{C}-\mathrm{H})$ and RSE to be calculated from ESR data by means of eqs 4 and 6 . Radicals bearing fluoro or amino substituents are nonplanar and do not meet the criteria for application of eqs 3-6. Although ${ }^{\circ} \mathrm{CR}^{1} \mathrm{R}^{2} \mathrm{OR}^{3}$ are nonplanar and do not meet the criteria, eq 4 may be applicable. Thus for $3 a$ eqs 4 and 6 give an RSE of $-5.6 \mathrm{kcal} / \mathrm{mol}$ and a BDE$(\mathrm{C}-\mathrm{H})$ of $93.9 \mathrm{kcal} / \mathrm{mol}$ in fair agreement with experiment ( -5.9 and $93.9 \mathrm{kcal} / \mathrm{mol}$, respectively). However, when the value of $\mathrm{a}\left(\mathrm{H}_{\alpha}\right)$ for $\mathbf{3 b}$ is substituted into eq 3 , the RSE obtained $(-14.8 \mathrm{kcal} / \mathrm{mol})$ is far too large.

Radicals 29-32 show how the above criteria may be applied to the estimation of RSE and BDE $(\mathrm{C}-\mathrm{H})$. Radical 29 has a $\left(\mathrm{H}_{\beta} \mathrm{Me}\right)=15.0 \mathrm{G}$ while $\mathbf{3 0}$ has $\mathrm{a}\left(\mathrm{H}_{\alpha}\right)=15.1$ G. ${ }^{23 b}$ As the pyramidalization quotient $\mathrm{P}^{\mathrm{t}}=0.99$, the values calculated from eqs $3-6$ of RSE $=-12.7 \mathrm{kcal} / \mathrm{mol}$ and $\mathrm{BDE}(\mathrm{C}-\mathrm{H})=83.1 \mathrm{kcal} / \mathrm{mol}$ for compound 29 , and $\mathrm{RSE}=-12.2 \mathrm{kcal} / \mathrm{mol}$ and $\mathrm{BDE}(\mathrm{C}-\mathrm{H})=86.7 \mathrm{kcal} / \mathrm{mol}$ for compound $\mathbf{3 0}$ may confidentally be accepted as correct to within $2 \mathrm{kcal} / \mathrm{mol}$. In accord with this conclusion, the two values of RSE are in close agreement, while the difference of $3.6 \mathrm{kcal} / \mathrm{mol}$ between the two values of $\operatorname{BDE}(\mathrm{C}-\mathrm{H})$ is about what would be expected between a secondary and a tertiary compound. Conversely, the values of $\mathrm{a}\left(\mathrm{H}_{\beta} \mathrm{Me}\right)=16.9 \mathrm{G}$ for $\mathbf{3 1}$ and $\mathrm{a}\left(\mathrm{H}_{\alpha}\right)=13.4 \mathrm{G}$ for $32^{23 \mathrm{~b}}$ give $\mathrm{P}^{\mathrm{t}}=1.26$ well outside the acceptable range. Clearly, $\mathbf{3 1}$ and $\mathbf{3 2}$ are significantly pyramidalized and the values calculated from eqs 3-6 for RSE $(-9.6$ and $-15.0 \mathrm{kcal} / \mathrm{mol}$ for 31 and 32$)$ and $\mathrm{BDE}(\mathrm{C}-\mathrm{H})(86.1$ and $84.0 \mathrm{kcal} / \mathrm{mol}$ for $\mathbf{3 1}$ and $\mathbf{3 2}$ ) must be erroneous.

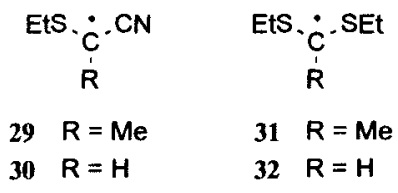

The data in Table 5 show some interesting trends. For example, protonation of $\alpha$-amino radicals removes the Ione pair from conjugation with the SOMO and virtually restores planarity. It should be possible to predict values of RSE and $\operatorname{BDE}(\mathrm{C}-\mathrm{H})$ for such species. Delocalization of the lone pair by acylation has a similar effect. Thus the 1-(acetamido)ethyl radical $\cdot{ }^{\circ} \mathrm{CHMeN} \mathrm{HCOCH}{ }_{3}$ meets the criteria for application of eqs 3-6 as does the formamido radical ${ }^{\circ} \mathrm{CHM}$ eNEtCOH. However, when the electron-attracting power of the carbonyl group is reduced by a second donor group as in the radical ${ }^{\circ} \mathrm{CHMeNH}$ $\mathrm{CONH}_{2}$, the nonplanarity is increased.

For oxygenated radicals the situation is less clear-cut. The radicals ${ }^{\circ} \mathrm{CHMeOCHO}$ and $\cdot \mathrm{CHMeSEt}$ just meet the critera, while the acetate, carbonate, carbamate, phosphate, and sulfoxy substituted radicals are slightly outside. The $\alpha$-bromo radical, ${ }^{\circ} \mathrm{CHMeBr}$, although possibly somewhat nonplanar, just meets the criteria.

\section{Conclusion}

The above discussion of the correlation of ESR hyperfine splitting constants with indices of radical stability and reactivity indicates that eqs 3 and 5 relating $a\left(H_{\alpha}\right)$ to RSE and $\mathrm{BDE}(\mathrm{C}-\mathrm{H})$ are applicable to a reasonable variety of substituted planar carbon-centered radicals 
including captodative radicals. Equation 7 relating a $\left(\mathrm{H}_{\alpha}\right)$ to $\mathrm{BDE}(\mathrm{C}-\mathrm{H})$ determined by Bordwell's method is also satisfactory over a similar range of radicals. Each of these equations fails for nonplanar radicals.

Values of a $\left(\mathrm{H}_{\beta} \mathrm{Me}\right)$ significantly less sensitive to derivations from planarity of the radical center provide more reliable indicators of RSE and $\mathrm{BDE}(\mathrm{C}-\mathrm{H})$ when substituted into eqs 4, 6, and 8. Although they can be applied to radicals which deviate slightly from planarity, they give erroneous results for significantly pyramidalized radicals. An indication of the degree of planarity and hence of the applicability of eqs 3-8 can be obtained from pyramidalization quotients $\left(\mathrm{P}^{\mathrm{t}}\right.$ and $\left.\mathrm{P}^{\mathrm{sec}}\right)$ derived from the ratio $\mathrm{a}\left(\mathrm{H}_{\beta} \mathrm{Me}\right) / \mathrm{a}\left(\mathrm{H}_{\alpha}\right)$ as shown in eqs 15 and 16 . Values of RSE and $\operatorname{BDE}(\mathrm{C}-\mathrm{H})$ can be confidently predicted within a range of $2 \mathrm{kcal} / \mathrm{mol}$ when $\mathrm{Psec}^{\mathrm{s}}<1.25$ or $\mathrm{P}^{\mathrm{t}}<$ I.05. All of the correlations fail for cyclic delocalized radicals, e.g., cyclopentadienyl, while significant differences between the literature values of $\mathrm{BDE}(\mathrm{C}-\mathrm{H})$ for some disubstituted species, e.g., ${ }^{\circ} \mathrm{CH}(\mathrm{COR})_{2}$, make it difficult to assess the accuracy of the correlations.

Since extensive compilations of ESR hyperfine splitting factors are now available, it should be possible to confidently estimate RSE and $\mathrm{BDE}(\mathrm{C}-\mathrm{H})$ for a very large number of radicals to within $2 \mathrm{kcal} / \mathrm{mol}$.

\section{Experimental Section}

ESR spectra were obtained on a Bruker ESR 420 spectrometer at an operation frequency of $9.3 \mathrm{GHz}$. All samples were recorded in quartz tubes. The samples were degassed by three cycles of freeze, pump, and thaw and filling with pure nitrogen. For photochemical reactions, the sample was irradiated with UV light inside the cavity of the spectrometer by means of a $1000 \mathrm{~W}$ high-pressure mercury lamp (Philips). The beam was passed through a water filter and then focused onto the sample by a system of two quartz lenses and a mirror. The temperature was controlled by a cooled or heated nitrogen flow (Bruker). Di-tert-butyl peroxide and halogenated solvents were filtered over basic alumina. All chemicals were purified by distillation or recrystallization. The spectra were simulated with the program NIEHS-WINSIM-EPR version 0.95.28 The abbreviations are as follows: DTBP, di-tert-butyl peroxide; Mod, modulation; Pow, microwave power; $T$, temperature (K); $C F$, center field; LS, line shape (\% Gaussian); LW, line width.

1-Methyl-1-(isopropoxy)ethyl (3a). Generated by UV irradiation of $200 \mu \mathrm{L}$ of diisopropyl ether with $200 \mu \mathrm{L}$ of DTBP: Mod, 0.32 G; T, 240; Pow, 6.4 mW. Simulation parameters: LS, 34\%; LW, $0.35 \mathrm{G} ; \mathrm{a}(6 \mathrm{H})=19.37 \mathrm{G}, \mathrm{a}(1 \mathrm{H})=0.93 \mathrm{G}$.

1-Amino-1-methylethyl (4a). Generated by UV irradiation of $60 \mu \mathrm{L}$ of isopropylamine with $170 \mu \mathrm{L}$ of DTBP: Mod, 1.0 G; T, 225; Pow, $6.4 \mathrm{~mW}$. Simulation parameters: LS, 78\%; LW, $0.35 \mathrm{G} ; \mathrm{a}(6 \mathrm{H})=17.90 \mathrm{G}, \mathrm{a}(\mathrm{N})=3.87 \mathrm{G}, \mathrm{a}(2 \mathrm{H})=2.20 \mathrm{G}$.

1-(Ethoxycarbonyl)ethyl (6b). Generated by UV irradiation of $50 \mu \mathrm{L}$ of ethyl 2-bromopropionate with $50 \mu \mathrm{L}$ of hexamethylditin in $150 \mu \mathrm{L}$ of DTBP: Mod, 0.5 G; T, 293; Pow, $6.4 \mathrm{~mW}$. Simulation parameters: LS, $100 \%$; LW, $0.11 \mathrm{G} ; \mathrm{a}(3 \mathrm{H})$ $=24.68 \mathrm{G}, \mathrm{a}(2 \mathrm{H})=1.31 \mathrm{G}, \mathrm{a}(1 \mathrm{H})=20.48 \mathrm{G}$. During the irradiation a white precipitate accumulated. The same radical

(28) NIEHS WINSIM EPR Version 0.95, Dave Duling, Laboratory of Molecular Biophysics NHEIOS, NIH, DHHS. could also be generated by UV irradiation of $150 \mu \mathrm{L}$ of ethyl 2-bromopropionate with $150 \mu \mathrm{L}$ of $\mathrm{Et}_{3} \mathrm{SiH}$ and $150 \mu \mathrm{L}$ of DTBP.

3-Methyl-2,5-pentanedion-3-yl (9a). Generated by UV irradiation of $30 \mu \mathrm{L}$ of 3-methyl-2,4-pentanedione with $150 \mu \mathrm{L}$ of DTBP and $2.4 \mathrm{mg}$ of trimethylamine-borane in $170 \mu \mathrm{L}$ of chlorobenzene: Mod, 1.0 G; T, 195; Pow, $10.1 \mathrm{~mW}$. Simulation parameters: LS, 52\%; LW, $0.43 \mathrm{G} ; \mathrm{a}(3 \mathrm{H})=21.52 \mathrm{G}, \mathrm{a}(6 \mathrm{H})=$ $0.1 \mathrm{G}$.

2,5-Pentanedion-3-yl (9b). Generated from $30 \mu \mathrm{L}$ of 2,5pentanedione by the method used for $9 \mathrm{9a}$ : Mod, $1.0 \mathrm{G}$; T, 195; Pow, $6.4 \mathrm{~mW}$. Simulation parameter: $\mathrm{a}(\mathrm{lH})=18.0 \mathrm{G}$. The intensity of the signal decreased rapidly during irradiation.

2-Acetyl-1-hydroxy-1-methylallyl (25). Generated by UV irradiation of $30 \mu \mathrm{L}$ of 3-methyl-2,4-pentanedione with $80 \mu \mathrm{L}$ of DTBP in $90 \mu \mathrm{L}$ of chlorobenzene: Mod, $0.5 \mathrm{G}$; T, 195; Pow, $10.1 \mathrm{~mW}$. Simulation parameters: CF, $3327.7 \mathrm{G}$; LS, 59\%; $L W, 0.20 \mathrm{G} ; \mathrm{a}(2 \mathrm{H})=16.25 \mathrm{G}, \mathrm{a}(1 \mathrm{H})=1.46 \mathrm{G}, \mathrm{a}(6 \mathrm{H})=3.23 \mathrm{G}$. The spectrum also showed the presence of $21 \%$ of 9a: CF, $3324.1 \mathrm{G}$.

1,1-Dicyanoethyl (10a). Generated by UV irradiation of a saturated solution of methylmalononitrile $\mathrm{e}^{29}$ in $200 \mu \mathrm{L}$ of $1: 1$ benzene/DTBP. The two layers so formed were irradiated inside the cavity of the spectrometer without separation: Mod, $0.5 \mathrm{G} ; \mathrm{T}, 305$; SW, $90 \mathrm{G}$; Pow, $6.4 \mathrm{~mW}$. Simulation parameters: LS, 0\%; LW, $0.11 \mathrm{G} ; \mathrm{a}(3 \mathrm{H})=20.64 \mathrm{G}, \mathrm{a}(2 \mathrm{~N})=2.64 \mathrm{G}$.

Dicyanomethyl (10b). Generated by UV irradiation of a saturated solution of malononitrile in $200 \mu \mathrm{L}$ of $1: 1$ benzene/ DTBP: Mod, 0.5 G; T, 280; Pow, $8.1 \mathrm{~mW}$. Simulation parameters: LS, 55\%; LW, $0.15 \mathrm{G} ; \mathrm{a}(3 \mathrm{H})=19.22 \mathrm{G}, \mathrm{a}(2 \mathrm{~N})=2.78 \mathrm{G}$. The solution became brown and the signal intensity decreased very rapidly.

1,4-Dibutyl-2,4-diketo-3,6-dimethylpiperazin-3-yl (12a). Generated by UV irradiation of $50 \mathrm{mg}$ of 1,4-dibutyl-3,6dimethyl pi perazine-2,5-dione with $150 \mathrm{mg}$ of DTBP: Mod, 1.0 G; T, 225; Pow, $9.96 \mathrm{~mW}$. Simulation parameters: LS, 100\%; LW, 1.2 G; a $(3 \mathrm{H})=17.8 \mathrm{G}$. After $10 \mathrm{~min}$ the solution became red and a second, persistent radical was formed.

1,4-Dibutyl-2,4-diketopiperazin-3-yl (12b). Generated by UV irradiation of $32 \mathrm{mg}$ of 1,4-dibutyl pi perazine-2,5-dione with $220 \mathrm{mg}$ of DTBP in $30 \mathrm{mg}$ of $\mathrm{CHCl}_{3}$ : $\mathrm{Mod}, 0.4 \mathrm{G}$; T, 253; Pow, $4 \mathrm{~mW}$. Simulation parameters: LS, 10\%; LW, $0.4 \mathrm{G} ; \mathrm{a}(\mathrm{H})$ $=17.1 \mathrm{G}, \mathrm{a}(2 \mathrm{H})=5.7 \mathrm{G}, \mathrm{a}(\mathrm{N})=1.2 \mathrm{G}, \mathrm{a}(2 \mathrm{H})=1.0 \mathrm{G}, \mathrm{a}(\mathrm{N})=$ $0.2 \mathrm{G}$.

9-Methylfluoren-9-yl (18a). Generated by heating of 70 mg of 9,9'-bis(9-methylfluorene) in $300 \mu \mathrm{L}$ of biphenyl ether: Mod, 0.4 G; T, 475; Pow, $5.1 \mathrm{~mW}$. Simulation parameters: LS, $100 \%$; LW, $0.21 \mathrm{G} ; \mathrm{a}(3 \mathrm{H})=14.56 \mathrm{G}, \mathrm{a}(2 \mathrm{H})=0.83 \mathrm{G}, \mathrm{a}(2 \mathrm{H})=$ $3.73 \mathrm{G}, \mathrm{a}(2 \mathrm{H})=0.81 \mathrm{G}, \mathrm{a}(2 \mathrm{H})=3.62 \mathrm{G}$.

$\mathrm{N}$-(1-E thoxycarbonylethyl)-N-(methyl)aminomethyl (27). Generated by UV irradiation of $50 \mu \mathrm{L}$ of the ethyl ester of DL-N,N-dimethylalanine in $150 \mu \mathrm{L}$ of DTBP: Pow, $8.1 \mathrm{~mW}$; T, 222. Simulation parameters: LS, 35\%; LW, $0.44 \mathrm{G} ; \mathrm{a}(2 \mathrm{H})$ $=14.30 \mathrm{G}, \mathrm{a}(3 \mathrm{H})=4.04 \mathrm{G}, \mathrm{a}(\mathrm{N})=7.00 \mathrm{G}, \mathrm{a}(\mathrm{HH})=1.34 \mathrm{G}$.

Acknowledgment. We thank the Deutsche Forschungsgemeinschaft and the Fonds der Chemischen Industrie for financial support. Part of this work was carried out while A.L.J.B. was a visitor at the Institut für Organische Chemie and Biochemie der Universität Freiburg. We thank the Alexander von Humbol dt Stiftung for an award to A.L.J.B.

\section{J O971940D}

(29) Diez-Barra, E.; de las Hoz, A.; Moreno, A.; Sánchez-Verdú, P. J . Chem. Soc., Perkin Trans. 1 1991, 2589-2592. 